\title{
Effects of Buoyancy on Lean Premixed V-flames, Part II: Velocity Statistics in Normal and Microgravity
}

\author{
R. K. Cheng, B. Bédat, D. T. Yegian \\ Environmental Energy Technologies Division \\ Ernest Orlando Lawrence Berkeley National Laboratory \\ Berkeley, CA 94720 \\ and \\ P. Greenberg \\ Microgravity Sciences Division \\ NASA Glenn Research Center \\ Cleveland, $\mathrm{OH} 44135$ \\ Corresponding Author: \\ Robert K. Cheng \\ Lawrence Berkeley National Laboratory \\ MS 70R0108B, 1 Cyclotron Rd. \\ Berkeley, CA 94720-8168 \\ Voice 15104865438 \\ Fax: $\quad 15104867303$ \\ E-Mail: RKCheng@,lbl.gov
}

\begin{abstract}
The field effects of buoyancy on laminar and turbulent premixed v-flames have been studied by the use of laser Doppler velocimetry to measure the velocity statistics in $+1 \mathrm{~g},-1 \mathrm{~g}$ and $\mu \mathrm{g}$ flames. The experimental conditions covered mean velocity, $U_{0}$, of 0.4 to $2 \mathrm{~m} / \mathrm{s}$, methane/air equivalence ratio, $\phi$, of 0.62 to 0.75 . The Reynolds numbers, from 625 to 3130 and the Richardson number from 0.05 to 1.34 . The results show that a change from favorable $(+1 \mathrm{~g})$ to unfavorable $(-1 \mathrm{~g})$ mean pressure gradient in the plume create stagnating flows in the farfield whose influences on the mean and fluctuating velocities persist in the nearfield even at the highest $R e$ we have investigated. The use of Richardson number $<0.1$ as a criterion for momentum dominance is not sufficient to prescribe an upper limit for these buoyancy effects. In $\mu \mathrm{g}$, the flows within the plumes are non-accelering and parallel. Therefore, velocity gradients and hence mean strain rates in the plumes of laboratory flames are direct consequences of buoyancy. Furthermore, the rms fluctuations in the plumes of $\mu \mathrm{g}$ flames are lower and more isotropic than in the laboratory flames to show that the unstable plumes in laboratory flames also induce velocity fluctuations. The phenomena influenced by buoyancy i.e. degree of flame wrinkling, flow acceleration, flow distribution, and turbulence production, can be subtle due to their close coupling with other flame flow interaction processes. But they cannot be ignored in fundamental studies or else the conclusions and insights would be ambiguous and not very meaningful.
\end{abstract}

Keywords: premixed flames, microgravity, turbulence statistics 


\section{Nomenclature}

$\begin{array}{ll}+1 g & \text { Normal gravity conditions } \\ -1 g & \text { Inverse gravity conditions, up-side-down flame } \\ \mu \mathrm{g} & \text { Microgravity conditions generated in aircraft flying in parabolic trajectories } \\ \mathrm{D} & \text { Burner diameter } \\ \mathrm{Q} & \text { Total reactants flow rate }(1 / \mathrm{s}) \\ \mathrm{U}_{\mathrm{o}} & \text { Mean exit velocity }(\mathrm{m} / \mathrm{s}) 4 \mathrm{Q} / \pi \mathrm{D}^{2} \\ \mathrm{Re} & \text { Reynolds number, } U_{o} D / v \\ \phi & \text { Equivalence ratio } \\ \tau & \text { heat release ratio, } T_{p} / T_{r}-1 \\ \mathrm{Ri} & \text { Richardson number, } g D \tau /(1+\tau) / U_{o}^{2} \\ \mathrm{~S}_{\mathrm{L}} & \text { Laminar flame speed } \\ \mathrm{u}_{\mathrm{n}} & \text { Convection velocity, }(g L \tau /(1+\tau))^{0.5} \\ \bar{c} & \text { Mean progress variable }=\left(T-T_{r}\right) /\left(T_{p}-T_{r}\right) \\ \mathrm{x}, \mathrm{U}, \mathrm{u}, & \text { Axial direction, its mean } \& \text { rms velocities } \\ \mathrm{y}, \mathrm{V}, \mathrm{v}, & \text { Transverse direction perpendicular to stabilizer, its mean \& rms velocities } \\ \mathrm{z}, \mathrm{W}, \mathrm{w}, & \text { Out-of-plane direction parallel to flame stabilizer, its mean \& rms velocities } \\ \mathrm{x} & \text { Distance along a streamline traced by LDV } \\ |\mathrm{x}| & \text { Absolute value of axial distance }|\mathrm{x}|=\left(\mathrm{x}^{2}\right)^{0.5} \\ |\mathrm{U}| & \text { Absolute value of axial velocity }|\mathrm{U}|=\left(\mathrm{U}^{2}\right)^{0.5} \\ |\mathrm{~W}| & \text { Absolute value of transverse velocity }|\mathrm{W}|=\left(\mathrm{W}^{2}\right)^{0.5} \\ S & \text { Mean flowspeed } S=\sqrt{U^{2}+V^{2}} \text { on x-y plane } \\ & \end{array}$

\section{Introduction}

In open flame systems, buoyancy is inherently coupled to the pressure field due to non-uniform density [1]. Our finding of a planar laminar flame in -1g stabilized solely by buoyancy forces [2] clearly demonstrates this coupling. Through its influences on downstream mean pressure gradients, buoyancy provides an upstream feedback mechanism that alters the flow and flame characteristics in the nearfield. As reported in Part I of this study [3], $+1 \mathrm{~g}$ and $-1 \mathrm{~g}$ turbulent V-flames have different flame wrinkle structures even in the nearfield. Therefore the field effects of buoyancy also extend to local turbulence/flame interactions. Consequently, flame stabilization limits, turbulent reaction rates and turbulence production and dissipation may also be directly or indirectly coupled with buoyancy. As the field effects of buoyancy have yet to be fully characterized and understood, this problem presents significant challenges to merging laboratory measurements with combustion models and numerical simulations. 
In our previous study [3], we investigated the overall scalar fields of premixed laminar and turbulent $v$-flames in $+1 \mathrm{~g},-1 \mathrm{~g}$ and $\mu \mathrm{g}$ environments by laser schlieren and planar laser induced fluorescence from $\mathrm{OH}(\mathrm{OH}-\mathrm{PLIF})$. The experimental conditions covered the regimes of momentum dominance $(R i<0.1)$ and buoyancy dominance $(R i>0.1)$ to determine their relative influences on the flame angles and turbulent wrinkle flame structures. We found that conditions at $R i \approx 1$, i.e. a balance between buoyancy force and initial flow momentum, were accessible only by laminar flames. In $-1 \mathrm{~g}$ the $R i=1$ laminar flame sheets were curled due to buoyant hot products pushing back against the reactants. With decreasing $R i$, the flame sheets were planar in the nearfield but remained curled in the farfield. These features show buoyancy influences diminishing in the nearfield as flow momentum increases. However we also found that the laminar and turbulent mean flame angles, $\alpha$, responded differently to buoyancy. For laminar flames, the $-1 \mathrm{~g}$ and $+1 \mathrm{~g}$ flame angles converged to the $\mu \mathrm{g}$ flame angle at the momentum limit $(R i=0)$ to indicate momentum overwhelming buoyancy. In turbulent flames, $+1 \mathrm{~g}$ and $1 \mathrm{~g}$ turbulent flame angles did not converge at $R i=0$. The OH-PLIF images showed that the inconsistency was due to the flamefronts becoming more wrinkled in $-1 \mathrm{~g}$ than in $+1 \mathrm{~g}$. As the Lewis number, Le, for these flames were all close to unity, differences in flame wrinkle development could not be attributed to the coupling between flamefront instability mechanisms with buoyancy. Moreover, the velocities near the burner exit were sufficiently fast such that Rayleigh-Taylor instabilities cannot account for these differences.

The objective of this paper is to obtain a better understanding of the field effects of buoyancy on laminar and turbulent $v$-flames by comparing their aerodynamic flowfields in $+1 \mathrm{~g},-1 \mathrm{~g}$ and $\mu \mathrm{g}$. In the laboratory, extensive measurements of the velocity statistics in $+1 \mathrm{~g}$ and $-1 \mathrm{~g}$ were obtained by the use of a two-component laser Doppler velocimetry system (LDV). Compare to previous v-flames studies, e.g., [4-6], the current measurement domains had been extended into the farfield. The larger domain allowed us to relate farfield features with those of the nearfield. For the $\mu \mathrm{g}$ experiments, a one-component as well as a two components LDV systems had been developed and used in parabolic aircraft flight experiments. As the implementation of LDV for parabolic flight is non-trivial, these LDV systems are described in more details.

\section{Laboratory Experimental Setup and LDV}

Details of the experimental apparatus and setup are described in Part I [3]. A brief description is given here. The burner is made of a cylindrical settling chamber attached to a converging nozzle with an exit port of $\mathrm{D}=25.4 \mathrm{~mm}$. Homogeneous mixtures of research grade methane and air were supplied at the bottom of the settling chamber. A perforated plate placed $16 \mathrm{~mm}$ upstream of the burner exit generated 
turbulence of $8 \%$ with an integral length scale of $3 \mathrm{~mm}$. The $\mathrm{V}$-flame stabilizer was a $2 \mathrm{~mm}$ rod placed across the center of the burner. For - $1 \mathrm{~g}$ experiments, the burner was inverted and submerged in a cooling water bath to prevent preheating of the reactants.

The laboratory LDV system consisted of a 4 Watt argon ion laser arranged in a standard four cross beam configuration. All beams were frequency shifted by Bragg cells ( $3 \mathrm{MHz}$ differential frequency for each component) to remove directional ambiguity with the $488 \mathrm{~nm}$ beams measuring the axial velocity component, $\mathrm{U}$, and the $514 \mathrm{~nm}$ beams measuring the transverse component, $\mathrm{V}$ and $\mathrm{W}$. The laser and the LDV optics were mounted on a traverse table controlled by a PC. Unconditioned joint velocity statistics were obtained by using $\mathrm{Al}_{2} \mathrm{O}_{3}$ seeds of nominally $0.3 \mu \mathrm{m}$ with the Doppler bursts analyzed by two TSI frequency counters based on a $10 \mu$ s coincidence criterion. The mean velocities, RMS velocities, and Reynolds stresses were deduced from either 1024 or 2048 pairs of validated samples.

In additional to scanning the velocities along fixed axial or traverse axes, mean flow paths through the flame brushes were also traced by a streamline tracking method [7, 8]. It employed a feedback protocol to translate the LDV probe in the direction of the local $2 \mathrm{D}$ velocity vector by a prescribed increment of $1.0 \mathrm{~mm}$. For the study of $-1 \mathrm{~g}$ flames, due to reduction in flow velocities and rapid changes in the flow directions within recirculating and stagnating regions, a $1.0 \mathrm{~mm}$ increment would be too large and inaccurate. The algorithm was modified to reduce the increments to $0.5 \mathrm{~mm}$ or $0.25 \mathrm{~mm}$ according to prescribed velocity thresholds.

The experimental conditions listed in Tables I and II cover flow rates, Q, of 0.2 to 1 1/s (mean exit velocity, $\mathrm{U}_{\mathrm{o}}$, of 0.4 to $2 \mathrm{~m} / \mathrm{s}$ ), and equivalence ratio, $\phi$, of 0.62 to 0.75 . The Reynolds numbers, $R e$, based on the burner diameter, $D$, are between 625 to 3130 and Richardson number, $R i$ are 0.05 to 1.34. Scalar properties of some of these flames were reported in Part I of this study [3]. For most cases, the overall features of the flowfields were investigated by making velocity measurements along two streamlines $\left(\mathrm{S}_{1}\right.$ and $\mathrm{S}_{2}$ ). Several flames were investigated in more detail by measuring in a fine $\mathrm{x}-\mathrm{y}$ grid. For a few selected cases, measurements were also made on the x-z plane parallel to the flame sheets and the stabilizer rod.

\section{$\mu \mathrm{g}$ Experimental Setup and LDV System}

The $\mu \mathrm{g}$ experimental package is shown in Figure 1. This compact module $(0.9 \mathrm{~m} \times 0.9 \mathrm{~m} \times 0.45 \mathrm{~m})$ was originally fitted with laser schlieren for drop tower experiments [9]. In conversion to LDV, a 2 axes computer controlled translation stage had been added to move the burner relative to the fixed LDV probe. The LDV optics and the ignitor were mounted on a platform with a center opening where the burner protruded. The translation stage, the flow-supply system (solenoids, valves, flow controllers and LDV 
seeder), and a central processing unit (CPU) were fitted below. A separate instrument rack (not shown) served as the control and monitoring center. It contained a "master" PC that interfaced with an experimental CPU, the laser power supply, and a second "slave" PC for LDV data acquisition. Aircraft safety provision does not permit a continuously lit flame. Therefore, the experiment was repeated for each parabola. The protocol consisted of the following setups: 1. Flow start-up. 2. Flame ignition. 3. Moving the burner to a preset measurement position. 4. Initiate LDV data collection for 10 or 15 second duration. 5. Flow shut down, and 6. Return the burner to its reference position. The data streams included the LDV bursts, time histories of the air and the fuel flow controllers, and the g-forces from accelerometer in three directions. During the 20 seconds low-gravity environment for each parabola, the average $g$ levels were between $-0.02 \mathrm{~g}$ to $+0.02 \mathrm{~g}$ with rms of $0.02 \mathrm{~g}$. Sometimes in rough weather, there were occassional $\mathrm{g}$-jitter spikes that were of the order of $\pm 0.2 \mathrm{~g}$. High g-spikes contribute additional velocity fluctuations estimated to be from 0.01 to $0.002 \mathrm{~m} / \mathrm{s}$ depending on the quality of the parabola. The recovery time to regain low $\mu \mathrm{g}$ levels is fast (within $0.01 \mathrm{sec}$ ) and the residual effect on the flame lasted for about $0.02 \mathrm{sec}$ based on flow residence time calculation. Therfore, in analyzing the LDV data, the accelerometer traces were used to filter out those data collected during the large g-spikes periods.

The implementation of LDV for $\mu \mathrm{g}$ experiments is non-trivial owing to the restrictive and rough environment of an aircraft in parabolic flight. Normal cabin vibrations, $+2 \mathrm{~g}$ forces during the pull-up phase of the parabola, and repeated rapid transitions from $+2 \mathrm{~g}$ to $\mu \mathrm{g}$ and back (up to 60 parabolas for each flight) can be detrimental to the alignments of sensitive optics. It was clear that the use of a bulky commercial LDV system would be impractical. Therefore we pursued a graded approach and started with the design and fabrication of a compact one-component (1-C) system to gain the experience necessary to adapt LDV to the parabolic flights. The custom designed 1-C LDV had a dual-beam forward scattering configuration. The laser source was an external cavity-doubled diode pumped Nd:YAG laser with $14 \mathrm{~mW}$ output at $532 \mathrm{~nm}$ (Adlas DPY 205C). The beam waist was positioned approximately coincident with the front focal plane of the decollimating lens to circumvent the need for mode match the output waist to the optical probe volume. An equal-path BK-7 splitting prism was utilized. It was fabricated to sufficient accuracy to provide suitable beam overlap at the probe volume without supplementary steering optics. The beams were brought to a focus with a $160 \mathrm{~mm}$ achromat, yielding a $1 / \mathrm{e}^{2}$ transverse probe volume dimension of approximately 150 microns.

The scattered light was collected at 15 degrees off the forward beam direction by a well corrected $55 \mathrm{~mm}$ focal length camera lens operating at F/2.8. The probe volume was imaged onto the input facet of a $100 \mu \mathrm{m}$ diameter multimode optical fiber. The conjugates of the collection lens were arranged such that the input facet of the fiber is spatially matched to the transverse dimension of the probe volume. The 
output of the fiber was coupled via a pair of high NA aspheric lenses to an avalanche photodiode detector (APD) (EG\&G C30921E). The APD was integrated with an AC coupled, matched impedance transconductance preamplifier (Analog Modules 712A). The signal was conditioned by a variable bandpass analog prefilter and was digitized by a dedicated burst spectral processor (QSP M240S). Individual Doppler bursts passing simultaneous amplitude and signal-to-noise threshold requirements were time stamped and stored directly into memory for subsequent post processing.

The 1-C LDV system was used in a series of preliminary $\mu \mathrm{g}$ v-flame experiments to evaluate the feasibility of deploying LDV in parabolic flights and to fine-tune the experimental protocol. We found that each aircraft parabola could afford measurement at only one position in the flowfield. This limitation was due mainly to non-uniform seeding rates in $\mu$ g (spouted bed seeder was difficult to control without gravity), and short $\mu \mathrm{g}$ duration for collecting sufficient samples to give stable statistical data at multiple points. We also concluded that frequency shifting (rotating grating or Bragg cells) to resolve directional ambiguity would not be practical. Therefore, in advancing to 2-component (2-C) LDV, we decided to use a non-shifting system. By arranging the two velocity components at $+/-45^{\circ}$ relative to vertical, the axial and radial velocities were directionally resolved from the algebraic combination of the outputs. Though, this 2-C LDV was not suitable for recirculating and stagnating regions, it was sufficient for investigating the $\mu \mathrm{g}$ v-flames flowfields where these flow features are not expected to be prevalent.

The 2-C LDV system was constructed using a pair of semiconductor diode lasers of $15 \mathrm{~mW}$ at 676 and $780 \mathrm{~nm}$. The diodes were temperature controlled to stabilize their output wavelengths, and were astigmatically corrected by a microlens bonded directly to the output facet (Blue Sky CircuLaser). The step curvature of the lens element also prevented back reflections from propagating into the laser cavity, the occurrence of which gave rise to observed fluctuations in the output coherence state. Temperature and current were regulated by a pair of compact controllers (ILX LDX-3100/LDT-5100).

The two beam paths were arranged coaxially through the use of an over-center dove prism. Equal-path BK-7 beam splitters were employed for both components. Separate mode matching optics for each channel provided commensurate transverse probe volume dimensions of $90 \mathrm{vm}$ with proper imaging of the beam waists. The $676 \mathrm{~nm}$ path utilized a pair of steering wedges to allow the individual probe volumes to be brought into spatial coincidence. Good optical beam quality was achieved, with the combined probe volume exhibiting a 98 percent best-fit to Gaussian, and a measured fringe broadening of less than one percent. The two transverse velocity components were angularly separated by $90^{\circ}$. The optical transmitter was rotated around its optical axis to orient the velocity components $+/-45^{\circ}$ relative to the axis of the burner. 
The scattered light was collected at 15 degrees off the forward beam direction by a well corrected 55 millimeter focal length camera lens operating at F/2.8. A dichroic filter was used to separate the scattered signal into its component wavelengths. A system of small relay lenses was necessary to place the dichroic element in a collimated beam path. The twin images of the probe volume were focused onto the input facets of two 100 micron diameter multimode optical fiber. The conjugates of the collection lens were arranged such that the input facets of the fibers were spatially matched to the transverse dimension of the probe volume.

The fibers were directly coupled in to a pair of custom-pigtailed, low SNR avalanche APDs (EG\&G C30902SQC) that were integrated into a pair of matched impedance, AC coupled transconductance preamplifiers (Analog Modules 712A). Variable bandpass analog anti-aliasing filters proceeded digitizing by the input section of dedicated burst spectral processor (QSP M240S). Coincidence gating was employed to reject bursts that did not simultaneously satisfy amplitude and SNR thresholds for both channels. Again, individual Doppler bursts meeting these requirements were time stamped and stored directly into memory for subsequent post processing.

\section{Results}

\section{Velocity Vectors of $+1 g$ and $-1 g$ Flames}

Figure 2 compares the 2D velocity vectors measured on the $x-y$ plane of $+1 g$ and $-1 \mathrm{~g}$ LVF0470. Also shown are the contours of the flow speed $\mathbf{S}$ and the outlines of the laminar flame fronts (solid lines) and two boundaries deduced from the schlieren images of $-1 \mathrm{~g}$ flame in Ref [3]. In $+1 \mathrm{~g}$, the velocity vectors of LVF0470 illustrate the salient features of the flowfield generated by V-flames. In the reactants outside of the flame front, the flow vectors are deflected outwards due to the oblique flame front behaving as an aerodynamic body. Across the flame front, the vectors change abruptly to inwards. This abrupt change is a characteristic feature of an oblique premixed flame front [5]. It is caused by a combination of combustion generated flow acceleration normal to the flame front and conservation of the velocity component tangential to the flame front. The outcome of this inward flow deflection is the formation of flow convergence in the plume. The central convergence zone continues to accelerate in the farfield as indicated by the velocity vectors and the $S$ contours.

When this flame is inverted, the effects of buoyancy on the flowfield of $-1 \mathrm{~g}$ LVF0470 are quite drastic. The flame front is pushed wide open and curls outwards. In response, outward flow deflection in the reactants increases to horizontal at the curled tip of the flame sheet. Inside the plume, a slightly converging flow is found only in the region adjacent to the stabilizer $(\mathrm{x}>-10 \mathrm{~mm}$ and $\mathrm{y}=0 \mathrm{~mm})$. Further downstream, the flow starts to decelerate and diverge due to the adverse mean pressure gradient generated 
by buoyancy. A stagnation point on the centerline is reached at about $\mathrm{x}=-34 \mathrm{~mm}$. The position is consistent with the plume boundary shown by schlieren. The stagnating plume eventually forces the products to vent around the water bath. This creates a large flow circulation centered at about $\mathrm{y}=25 \mathrm{~mm}$ $\mathrm{x}=-15 \mathrm{~mm}$ near the top edge of the $-1 \mathrm{~g}$ flame sheet. The schlieren image also shows a non-reacting boundary formed between the hot recirculating products and the cold reactants. This boundary is coincidental to the $S=1 \mathrm{~m} / \mathrm{s}$ contour that outlines the edge of the reactants stream. Despite the differences between the flowfields of $+1 \mathrm{~g}$ and $-1 \mathrm{~g}$ LVF0470, a common feature is that the $S$ contours in the products regions are generally parallel to the flame fronts. This seems to indicate a potential flow behavior with the flame front acting as a line source for the flow in the plume.

The $x-y$ velocity vectors and S contours for $+1 \mathrm{~g}$ and $-1 \mathrm{~g}$ TVF1065 are shown in Figure 3. Also plotted are the silhouettes of the turbulent flame brushes deduced from schlieren. Due to a low Ri of 0.05, the differences between the $+1 \mathrm{~g}$ and $-1 \mathrm{~g}$ mean velocity vectors are less obvious. Both $+1 \mathrm{~g}$ and $-1 \mathrm{~g}$ flames show gradual changes in flow direction from outwards (reactants) to inwards (products) through the broaden flame brushes. The changes are not abrupt due to the fact that the mean velocities within the flame brushes consist of intermittent contributions from the conditional velocities in the reactants, $U_{r}$ and in the products, $U_{p}$ on either sides of the fluctuating wrinkled flame fronts [5]. Though the instantaneous jump across the flame fronts may be comparable to that of a laminar flame, the intermittent nature results in a mean velocity that is proportional to $\mathrm{U}=(1-\bar{c}) \mathrm{U}_{\mathrm{r}}+\bar{c} \mathrm{U}_{\mathrm{P}}$ where $\bar{c}$ is a mean conserved scalar. The gradual change in the velocity vector from outwards to inwards corresponds to $\bar{c}$ varying through the broaden flame brush from 0 in the reactants to 1 in products.

In the products zone, the formation of an accelerating plume is shown for the $+1 \mathrm{~g}$ flame. In comparison, the $\mathrm{S}$ contours in the plume of the $-1 \mathrm{~g}$ flame shows it to be decelerating but the features of a diverging flow do not appear until far downstream at $\mathrm{x}<-55 \mathrm{~mm}$. Consequently, a downstream stagnation point is not found because it formed outside the measurement domain. At the far end of our measurement domain $(|\mathrm{x}| \approx 70 \mathrm{~mm})$, the difference in $S$ for the $+1 \mathrm{~g}$ and $-1 \mathrm{~g}$ TVF1065 is about $1 \mathrm{~m} / \mathrm{s}$ at the centerline. As in the $-1 \mathrm{~g}$ laminar flame, an outer recirculation zone is also form in $-1 \mathrm{~g}$ near the top edge of the flame brush and the velocity vectors on the side boundary at $\mathrm{y}=40 \mathrm{~mm}$ show a strong flow reversal region.

\section{Streamlines of $+1 g$ and $-1 g$ flames}

The mean streamlines offer a convenient means to determine how buoyancy effects on the mean flowfields evolve with increasing flow momentum. Differences in $+1 \mathrm{~g}$ and $-1 \mathrm{~g}$ flow patterns are shown by complementary sets of streamlines traced from the same origins. Shown in Figure 4 are the results obtained in four laminar cases all with $\phi=0.7$. Schlieren images of three of these flames can be found in Figure 3 of Ref [3]. For each pair of $+1 \mathrm{~g}$ and $-1 \mathrm{~g}$ flames, two streamlines have been obtained. The inner 
streamlines, $S_{1}$, originated at $|x|=6 \mathrm{~mm}$ and $y=4 \mathrm{~mm}$, and the outer streamlines, $S_{2}$, originated at $|x|=6$ $\mathrm{mm}$ and $\mathrm{y}=7 \mathrm{~mm}$.

For the buoyancy dominant LVF0270 $(R i=1.34)$, the $+1 \mathrm{~g}$ and $-1 \mathrm{~g}$ streamlines are intertwined showing significant buoyancy effects throughout the flowfield. Focusing first on the $\mathrm{S}_{2}$ for $+1 \mathrm{~g}$ LVF0270, it encapsulates typical features of the flow patterns through v-flames [6]. Initially, it tracks outward due to the flow deflection in the reactants. A bend at $|x|=14 \mathrm{~mm}$ and $\mathrm{y}=10 \mathrm{~mm}$ marks the location of the flame sheet. Then the flow tracks inwards showing the formation of a flow convergence in the products region. In comparison, the most notable feature of $S_{1}$ and $S_{2}$ for $-1 g$ LVF0270 is their relatively short lengths with their truncation points representing the positions near the stagnating boundary. Despite the stagnating plume downstream, a characteristic bend is still discernable on $\mathrm{S}_{2}{ }^{1}$ But its location $(|\mathrm{x}|=8$ $\mathrm{mm})$ is much lower than that of the $+1 \mathrm{~g}$ flame $(|\mathrm{x}|=14 \mathrm{~mm})$ due to buoyancy forcing the flame sheets to spread open and curled. In the products zone of $-1 \mathrm{~g}$ VF2070, both $\mathrm{S}_{1}$ and $\mathrm{S}_{2}$ continue to track outwards as expected of a stagnating flow.

For the cases at lower $R i$ (LVF0470, LVF0670 and LVF0870), lengthening of the $-1 \mathrm{~g}$ flame streamlines with reducing $R i$ shows the stagnating product/air boundary being pushed further downstream. However, deviations between the $+1 \mathrm{~g}$ and $-1 \mathrm{~g}$ streamlines persistent to show buoyancy influence in the nearfield. Compared to the $+1 \mathrm{~g}$ streamlines, all $-1 \mathrm{~g}$ streamlines have higher degrees of outward flow deflection in the reactants and continuous diverging trends in the products. At the highest Re we have investigated $(R i=0.084)$ the corresponding laminar flame angles of $+1 \mathrm{~g}$ and $-1 \mathrm{~g}$ LVF8070 are essentially the same [3]. Yet their streamlines are quite different. Therefore, momentum domination as implied by the $R i<0.1$ criterion seem to be valid only in the nearfield region adjacent to the flame stabilizer.

Comparison of the $+1 \mathrm{~g}$ and $-1 \mathrm{~g}$ streamlines in turbulent v-flames are shown in Figure 5 . As in the laminar cases, all streamlines have initial outward tracks in the nearfield. As to be expected, the characteristic bends in the $+1 \mathrm{~g}$ streamlines through the flame brushes are less abrupt than in the laminar cases. However, only the inner streamlines $\left(\mathrm{S}_{1}\right)$ of the $-1 \mathrm{~g}$ flames show inward deflections following the bends. All the outer $-1 \mathrm{~g}$ streamlines $\left(\mathrm{S}_{2}\right)$ continue to track outwards. This is because the outer streamlines enter the turbulent flame brush near its top edge where the $-1 \mathrm{~g}$ wrinkled flame fronts experience large excursions due to the Rayleigh/Taylor type instability (as seen from our previous OH-PLIP results) and

\footnotetext{
${ }^{1}$ The characteristic bend, however, is not shown by $\mathrm{S}_{1}$ of $-1 \mathrm{~g}$ LVF2070 because the flame is below its origin.
} 
also to the influence of the outer recirculation regions (as seen from 2D velocity vectors). Consequently, the instantaneous contributions from the velocity jumps across flame fronts become insignificant.

For all three turbulent flames, the $+1 \mathrm{~g}$ and $-1 \mathrm{~g}$ streamlines are quite consistent in the nearfield. Though this may suggest momentum domination in the nearfield, a comparison with the streamlines of $+1 \mathrm{~g}$ and $-1 \mathrm{~g}$ laminar flames at the same $R i$ casts doubt on this interpretation. As seen in Figure 4, the streamlines of LVF 0670 and LVF0870 (with the same Re and comparable Ri as TVF0665, and TVF0865 respectively) show quite different flow paths in $+1 \mathrm{~g}$ and $-1 \mathrm{~g}$. As discussed previously [3], turbulence provides an additional mechanisms for buoyancy forces to act on. A lack of significant differences between the mean streamlines of $+1 \mathrm{~g}$ and $-1 \mathrm{~g}$ turbulent $\mathrm{v}$-flames implies that steering of the mean flow direction is no longer the main manifestation of buoyancy effects. The mean and rms velocity profiles along the streamline will provide further evidence to support this notion.

Profiles of the flowspeed, S, and the axial u' and transverse v' rms velocities along the streamlines of LVF0670 are shown in Figure 6. At $x^{*}=0$, all the S profiles in Figure 6(a) are at the same level of $1.5 \mathrm{~m} / \mathrm{s}$ and they remain constant until the streamlines enter the flame fronts whose positions are marked by abrupt jumps induced by combustion heat release. Therefore, the main contribution of buoyancy to the nearfield of laminar v-flames is to steer the mean flow direction without changing the flowspeed. The magnitudes of the velocity jumps on both $+1 \mathrm{~g}$ LVF0670 profiles are the same and show that the properties along the flame front to be uniform. In the post flame products region, both S profiles of the $+1 \mathrm{~g}$ flame increase linearly to show acceleration in the buoyant plume. In contrast, the flowspeed jumps on the $-1 \mathrm{~g}$ LVF0670 S profiles are lower than those of the corresponding $+1 \mathrm{~g}$ flame and the jump on the $S_{2}$ profile is barely discernable. The reduction in the flowspeed jumps across the $-1 \mathrm{~g}$ laminar flame is most likely associated with buoyancy forces counteracting the flame generated flow acceleration as well as flame curvature and local stretch. In the post flame region, rapid decreases in the $-1 \mathrm{~g}$ S profiles are consistent with flow deceleration and divergence in the plume.

In Figure 6(b), the u' profiles of $+1 \mathrm{~g}$ LVF0670 have a distinctive increasing trend beginning at $\mathrm{x}^{*}=20 \mathrm{~mm}$ that illustrates a dominance of the pulsating plume in the farfield. The corresponding v' profiles of Figure 6(c), however, remain relative flat. Therefore, the contributions from the unstable $+1 \mathrm{~g}$ plume are biased towards the axial direction. In comparison, the u' and v' profiles of -1g LVF0670 shown in Figures 6 (b) and (c) are characterized by many local spikes. The u' and v' spikes appearing at $\mathrm{x}^{*}>20 \mathrm{~mm}$ are in the plume and caused by the unstable fluctuating products/air interface near the stagnation line. The u' and v' spikes centered at $\mathrm{x}^{*}=15 \mathrm{~mm}$, however, correspond to the flowspeed jump (i.e. flame front position) on the outer streamline of the $-1 \mathrm{~g}$ flame. The appearance of these spikes means 
that the $-1 \mathrm{~g}$ flame front is not stationary and thus inflicting conditional sampling of $U_{\mathrm{r}}$ and $U_{\mathrm{P}}$ that causes the local u' and v' spikes.

Figure 7 compares the $S$, u' and v' profiles along the streamlines of $+1 \mathrm{~g}$ and $-1 \mathrm{~g}$ TVF0665. For the turbulent flames, their $S$ profiles do not have consistent features. In Figure 7(a), the profiles along $\mathrm{S}_{1}$ for both the $+1 \mathrm{~g}$ and the $-1 \mathrm{~g}$ flames start at the same level but deviate almost immediately downstream. The $-\lg S$ profile is first to increase at $\mathrm{x}^{*} \approx 6 \mathrm{~mm}$ and the increase in the $+1 \mathrm{~g} S$ profile occurs further downstream at $x^{*} \approx 12 \mathrm{~mm}$. These increases are associated with combustion heat release within the flame brushes. Differences in their positions on the $+1 \mathrm{~g}$ and $-1 \mathrm{~g}$ profiles along $\mathrm{S}_{1}$ are in accord with previous OH-PLIF images showing that turbulent flame wrinkles evolve more quickly in $-1 \mathrm{~g}$ causing the leading edge of the flame brush to shift upstream. In the post flame brush regions, the $-1 \mathrm{~g} S$ profile for $\mathrm{S}_{1}$ decelerates while the corresponding $+1 \mathrm{~g}$ profile accelerates slightly. These features are again consistent with buoyancy generating favorable $(+1 \mathrm{~g})$ or adverse $(-1 \mathrm{~g})$ mean pressure gradients.

Along the outer streamlines $\mathrm{S}_{2}$, the- $\lg S$ profile starts at a higher level than the $+\lg S$ profile. Due to the fact that these $S$ profiles both originated in the reactants, this discrepancy shows that the cross stream distributions of the exit flows have been altered. Moreover, neither S profile has the characteristic increase that marks the turbulent flame brush. $\mathrm{In}+1 \mathrm{~g}$, the $\mathrm{S}$ profiles for $\mathrm{S}_{2}$ has a very moderate rise then remains constant beyond the flame brush (the flame brush position is estimated to be around $\mathrm{x}^{*}>30 \mathrm{~mm}$ according to the bend shown on Figure 3(a)). The $-1 \mathrm{~g} \mathrm{~S}$ profile for $\mathrm{S}_{2}$ remains flat from $\mathrm{x}^{*}>0$ and then decelerates at $x^{*}>30 \mathrm{~mm}$. A lack of features on these $S$ profiles is not very surprising considering the fact that $\mathrm{S}_{2}$ tracks near the top edges of the flame brushes where the flame/flow dynamics are greatly influence by instabilities in the mixing shear layer (in $+1 g$ ) or in the recirculation zone (in $-1 \mathrm{~g}$ ). As to the u' and v' profiles in Figures 7 (b) and (c), they all show rapidly decreases in the nearfield and level to constant values in the farfield. It is interesting to note that the laminar LVF0670 of Figure 6 and the turbulent TVF0665 of Figure 7 have the same Re and their $+1 \mathrm{~g}$ cases attain the same $u$ ' fluctuation levels in the farfield (about $\mathrm{u}^{\prime}=0.4 \mathrm{~m} / \mathrm{s}$ at $\mathrm{x}^{*}=60 \mathrm{~mm}$ ). This observation suggests initial dissipation of turbulence and subsequent generation of flow fluctuations by the unstable plumes.

\section{Profiles of laminar $\mu \mathrm{g}$ flame}

As described in the Experimental section, each velocity data point for the $\mu \mathrm{g}$ flame was collected during separate aircraft parabolas. Despite occasional flame-off and failed ignitions caused by flow control jitters and electronic interferences from other experiments on the aircraft, a lack of significant scatter in the $\mu \mathrm{g}$ data of Figure 8 indicates that the experiments were highly reproducible. The main operational difficulty encountered during the aircraft experiments was the maintenance of a constant seeding rate. 
Consequently, the number of LDV validations used to compute the velocity statistics for the $\mu \mathrm{g}$ flames was not consistent from point to point. Typical number of joint velocity validations collected during a 10 seconds sampling period was about 350 but could varied from 200 to 1000 . These numbers were lower than the joint validations (1024 and 2048) obtained in laboratory flames. Given the restrictive and challenging environment of the parabolic flights for LDV measurements, this was an unavoidable but acceptable compromise.

Figure 8 shows the centerline profiles of laminar LVF06701 in $+1 \mathrm{~g},-1 \mathrm{~g}$ and $\mu \mathrm{g}$. From Figure 8 (a) it can be seen that the overall features of the $|\mathrm{U}|$ profile in $\mu \mathrm{g}$ resemble those of the $+1 \mathrm{~g}$ flame. In the nearfield at $|\mathrm{x}|<15 \mathrm{~mm}$, the $+1 \mathrm{~g}$ and $\mu \mathrm{g}$ profiles differ by only $0.25 \mathrm{~m} / \mathrm{s}$ whereas the $-1 \mathrm{~g}$ profile is about $0.75 \mathrm{~m} / \mathrm{s}$ lower. Without buoyancy contributions, the $\mu \mathrm{g}|\mathrm{U}|$ profile attains a constant level of $|\mathrm{U}| \approx 2 \mathrm{~m} / \mathrm{s}$ at $|\mathrm{x}|>$ $20 \mathrm{~mm}$. To estimate if the differences between the $+1 \mathrm{~g},-1 \mathrm{~g}$ and $\mu \mathrm{g}$ centerline profiles are comparable to buoyancy induced convection, we calculated the natural convection velocity $u_{N}=(g L \tau /(1+\tau))^{1 / 2}$ along the centerline by substituting $|\mathrm{x}|$ for the independent variable $L$. Adding to or subtracting $\boldsymbol{u}_{N}(|\mathrm{x}|)$ from the $\mu \mathrm{g}|\mathrm{U}|$ profile will show if this approximation can provide some useful insights. The two lines in Figure 8(a) above and below the $\mu \mathrm{g}$ profiles are the results of adding and subtracting $\boldsymbol{u}_{N}$ from $\mu \mathrm{g}|\mathrm{U}|$ profile. It can be seen that the upper dashed line gives a fair approximation of the $+1 \mathrm{~g}$ profile though it tends to slightly overestimate the $+1 \mathrm{~g}$ velocities in the nearfield. On the other hand, the lower solid line is close to- $1 \mathrm{~g}|\mathrm{U}|$ profile only at $|\mathrm{x}|=15 \mathrm{~mm}$ where, according to Figure 5, the flow in the hot products of $+1 \mathrm{~g}$ and $-1 \mathrm{~g}$ laminar flames are both convergent. In the farfield, the subtraction of $\boldsymbol{u}_{N}$ from the $\mu \mathrm{g}|\mathrm{U}|$ profile significantly underestimates the deceleration found in the divergent plume of $-1 \mathrm{~g}$ LVF0670. The large disparity demonstrates that the simple 1D $\boldsymbol{u}_{N}$ approximation fails once the field effects of gravity generates significant flow divergence in the $-1 \mathrm{~g}$ flame.

In Figure 8 (b) and (c), both u' and v' profiles for the $\mu \mathrm{g}$ flame are below $0.15 \mathrm{~m} / \mathrm{s}$ and remain at these low levels throughout to show that the plume of $\mu \mathrm{g}$ LVF0670 remains stable and laminar. In contract, the u' and v' profiles for the $+1 \mathrm{~g}$ flames show increases with increasing $|\mathrm{x}|$. These increases show that the pulsating plume contributes to velocity fluctuations. At $|x|=60 \mathrm{~mm}$, the velocity fluctuations have a slight anisotropy with u' about $25 \%$ higher than v'. In $-1 \mathrm{~g}$, the increases in velocity fluctuations are even higher with both u' and v' rising abruptly at $|\mathrm{x}| \approx 20 \mathrm{~mm}$. This is also the position where the mean flow begins to diverge and seems to be a demarcation for the momentum dominant nearfield and buoyancy dominant farfield regions. The highest $u$ ' and v' levels in the $-1 \mathrm{~g}$ LVF0670 plume are about twice the levels found in the corresponding $+1 \mathrm{~g}$ flame and can be attributed to the inherent Rayleigh-Taylor instability. 
Transverse profiles measured at two axial locations $(|x|=20$ and $40 \mathrm{~mm})$ of LVF0670 are plotted in Figures 9 and 10. From Figures 9 (a) and (b), the $U$ and V profiles at $|x|=20 \mathrm{~mm}$ show that the nearfield of the $\mu \mathrm{g}$ flame closely resembles that of the $+1 \mathrm{~g}$ flame. Both $+1 \mathrm{~g}$ and $\mu \mathrm{g}|\mathrm{U}|$ profiles have a relative flat center region near $\mathrm{y}=0$ and then drop through the flame zone to a shoulder region representing the reactants. Further drop in $|\mathrm{U}|$ near $\mathrm{y} \approx 15 \mathrm{~mm}$ is associated with the mixing region formed between the reactants and the ambient air. The corresponding V profiles for the $+1 \mathrm{~g}$ and $\mu \mathrm{g}$ flames both show the characteristics shape consistent with flame generated flow deflection from outward (positive $\mathrm{V}$ ) to inward (negative $\mathrm{V}$ ) across the flame front. The zero crossing point is a convenient marker for the flame front position. A slight difference in this position on the $+1 \mathrm{~g}$ and $\mu \mathrm{g}$ flames $\mathrm{V}$ profiles is consistent with previous conclusion that their flame angles should be very close under this condition with $\mathrm{Ri}=0.15$ [3]. In contrast, the $|\mathrm{U}|$ and $V$ profiles of the $-1 \mathrm{~g}$ LVF0670 at $|\mathrm{x}|=20 \mathrm{~mm}$ have quite different shapes. There is a noticeable velocity deficit in the $|\mathrm{U}|$ profile at $\mathrm{y}=0 \mathrm{~mm}$. The corresponding $\mathrm{V}$ profile is devoid of the characteristic shape associated with flame generated flow deflection and is more consistent with a divergent flow. These changes occurred despite the fact that the flame angle of -1g LVF0670 differs only $1.5^{\circ}$ from that of the $+1 \mathrm{~g}$ flame [3]. The $\mathrm{u}^{\prime}$ and $\mathrm{v}^{\prime}$ profiles at $|\mathrm{x}|=20 \mathrm{~mm}$ in Figures 9 (c) and (d) show again that flow fluctuations are higher in the two buoyant flames with turbulence levels almost constant across the plume. A notable feature of the u' and v' profiles for the $\mu \mathrm{g}$ LVF0670 is their small local peaks at $y=8 \mathrm{~mm}$. This position is at the center of the flame front with the steepest velocity gradients. Slight flame front movement is registered by local u' and v' peaks as is shown here. Therefore, the $\mu \mathrm{g}$ flame front has some slight movements probably due to g-jitter of the aircraft. The fact that our LDV system was sufficient robust to resolve details of the flowfield gives credence to our microgravity results.

Further downstream at $|\mathrm{x}|=40 \mathrm{~mm}$, the transverse $|\mathrm{U}|$ profiles for the $+1 \mathrm{~g}$ and the $\mu \mathrm{g}$ LVF0670 (Figure 10 (a)) show that their farfield have evolved differently. Without buoyancy contribution, a flat distribution dominates the $\mu \mathrm{g}|\mathrm{U}|$ profile whereas the $+1 \mathrm{~g}|\mathrm{U}|$ profile has a central dome representing flow converging towards the plane of symmetry. In contrast, the $-1 \mathrm{~g}|\mathrm{U}|$ profile has dropped to very low levels of $0<|\mathrm{U}|<$ $0.5 \mathrm{~m} / \mathrm{s}$ and is relatively flat. In Figure 10 (b), the zero crossing points on the V profiles of $+1 \mathrm{~g}$ and $\mu \mathrm{g}$ LVF0670 are identical and show that buoyancy does not alter the flame orientation. Due to the fact that at $|x|=40 \mathrm{~mm}$, the flame fronts are situated close to the edge of the measurement domain $(y=20 \mathrm{~mm})$, this set of data does not cover the reactants. But within the products, there is only a very slight inward deflection (i.e. negative $\mathrm{V}$ ) in the $\mu \mathrm{g}$ flame. In $-1 \mathrm{~g}$, the flame front extends even further out and the measurement domain only captured flow within the products. Consequently, the V profile of $-1 \mathrm{~g}$ LVF0670 in Figure 10 (b) has typical divergent flow features. In Figure 10 (c) and (d), except for slight increases in the fluctuation levels, the distributions of $\mathrm{u}^{\prime}$ and v' profiles at $|\mathrm{x}|=40 \mathrm{~mm}$ for the $+1 \mathrm{~g}$ and 
$-1 \mathrm{~g}$ flames are not significant differently than those measured in the nearfield (see Figure 9 (c) and (d). In $\mu \mathrm{g}$, v' profile has an increase at $\mathrm{y}>10 \mathrm{~mm}$. This is most like associated with flow fluctuations generated by entrainment of the ambient air.

\section{Profiles of turbulent $\mu \mathrm{g}$ flame}

The centerline profiles measured in $+1 \mathrm{~g},-1 \mathrm{~g}$ and in $\mu \mathrm{g}$ TVF0975 are shown in Figure 11. Compare to the laminar profiles of Figure 8 (a), the three $|\mathrm{U}|$ profiles are more consistent at the momentum dominant nearfield of $|\mathrm{x}|<15 \mathrm{~mm}$. Deviation of the three $|\mathrm{U}|$ profiles occurs further downstream at $|\mathrm{x}|>15 \mathrm{~mm}$. As to be expected, the $+\lg |\mathrm{U}|$ profile attains velocities higher than in the $\mu \mathrm{g}$ flame. Differences between the two profiles are approximately equal to the contributions of the natural convection velocity shown by the dashed line. The implication is that the first order effect of buoyancy on $+1 \mathrm{~g}$ turbulent flame is to accelerate the flow in the plume. In comparison, the deceleration found in the $-1 \mathrm{~g}$ turbulent flame cannot be predicted by removing the contribution from $\boldsymbol{u}_{\boldsymbol{n}}$ because of the generation of significant flow divergence in the farfield region.

The u' and v' profiles of Figure 11 (b) and (c) illustrate a persistent influence of buoyancy on the velocity fluctuations in the plumes. Without buoyancy contributions, u' and v' profiles of the $\mu \mathrm{g}$ flame are relatively flat within the plume (i.e. $|\mathrm{x}|>15 \mathrm{~mm}$ ) with both their mean levels at about $0.15 \mathrm{~m} / \mathrm{s}$. This is lower than the freestream turbulence of $\mathrm{u}^{\prime}=\mathrm{v}^{\prime}=0.3 \mathrm{~m} / \mathrm{s}$ and is in accord with the notion of turbulence dissipation due to the higher viscosity in the products. In $+1 \mathrm{~g}$, the $\mathrm{u}^{\prime}$ profile of Figure 11 (b) is consistently higher than in $\mu \mathrm{g}$ and shows an increasing trend at $|\mathrm{x}|>30 \mathrm{~mm}$. But the corresponding $+1 \mathrm{~g} \mathrm{v}$ ' profile (Figure 11 (C)) is only slightly higher than in the $\mu \mathrm{g}$ flame but remains relatively flat with increasing $|\mathrm{x}|$. Therefore, the flow fluctuations generated by the pulsating plume is again confined to the axial direction. In $-1 \mathrm{~g}$, increases in both u' and v' are found in the farfield with u' and v' reaching respectively to 0.4 and $0.3 \mathrm{~m} / \mathrm{s}$.

These results demonstrate the significance of buoyancy in controlling the flowfield dynamics in the plumes. This aspect of flame generated turbulence has yet to be investigated theoretically and numerically. In previous studies, the higher turbulence levels measured in the products regions of premixed turbulent have been attributed to flame flow interaction processes such as vorticity production due to baroclinicity $[6,10,11]$ and to the kinematics fluid motions associated with gas expansion [12]. In light of our $\mu \mathrm{g}$ flame data, the contributions of these turbulent production mechanisms can be overstated if buoyancy contributions are not taken into consideration. Due to the fact that the pulsation frequencies of the buoyant $+1 \mathrm{~g}$ plumes are between 10 to $20 \mathrm{~Hz}$, analyzing the velocity spectra will be very useful to separate the contributions and to gain better physical insights. 
Transverse profiles of $+1 \mathrm{~g},-1 \mathrm{~g}$ and $\mu \mathrm{g}$ TVF0975 at $|\mathrm{x}|=20$ and $40 \mathrm{~mm}$ are shown respectively in Figure 12 and 13. In Figure 12, the overall features of the $|\mathrm{U}|, \mathrm{V}, \mathrm{u}$ ' and $\mathrm{v}^{\prime}$ profiles at $|\mathrm{x}|=20 \mathrm{~mm}$ for all three cases are quite similar. The $|\mathrm{U}|$ profiles on Figure 12 (a) have minor differences with the buoyant flames showing central domes at $\mathrm{y}=0$ while the $\mu \mathrm{g}$ profile has a relatively flat center region. Towards the sides, the $-1 \mathrm{~g}$ profile falls off more rapidly than the $+1 \mathrm{~g}$ and $\mu \mathrm{g}$ profiles. All the corresponding $\mathrm{V}$ profiles (Figure 12 (b)) exhibit a characteristic shape associated with flame generated flow deflection with the $+1 \mathrm{~g}$ and $\mu \mathrm{g}$ profiles being almost identical. The $-1 \mathrm{~g} \mathrm{~V}$ profile, however, has a higher peak to trough difference. The distance between the positions of the peak and the trough is also larger than in the $+1 \mathrm{~g}$ and $\mu \mathrm{g}$ flames. This is consistent with flame brush broadening due to a higher degree of flame wrinkling as seen from previous OH-PLIF imaging results. In Figure 12 (c) and (d) all the u' and v' profiles show velocity fluctuations increasing towards the outer edges of the reactant stream. They are also devoid of pronounced peaks near the center of the flame brushes (i.e. near the zero crossing points of the V profiles at about $\mathrm{y}=6$ to $8 \mathrm{~mm}$ ) and indicate that the intermittent contributions to $\mathrm{u}$ ' and $\mathrm{v}$ ' from conditioned mean velocities are small.

Further downstream at $|\mathrm{x}|=40 \mathrm{~mm}$, the differences between the mean $|\mathrm{U}|$ and $\mathrm{V}$ profiles of $+1 \mathrm{~g},-1 \mathrm{~g}$ and $\mu g$ TVF0975 are more significant (Figure 13 (a) and (b)). In -1g, the $|\mathrm{U}|$ profile (Figure 13(a)) assumes a relatively flat distribution. Though the $+\lg$ and the $\mu \mathrm{g}|\mathrm{U}|$ profiles retain the same general shape as in Figure 12 (a), a flat region near $\mathrm{y}=0 \mathrm{~mm}$ in $\mu \mathrm{g}$ is more clearly defined. In Figure 13 (b), all three V profiles indicate a weakening of flame generated flow deflection. For the $+1 \mathrm{~g}$ flame, the $\mathrm{V}$ profile retains the characteristics shape but the magnitude of the deflection is reduced from a peak to trough value of $1.1 \mathrm{~m} / \mathrm{s}$ at $|\mathrm{x}|=20$ to $0.6 \mathrm{~m} / \mathrm{s}$ at $|\mathrm{x}|=40 \mathrm{~mm}$. In $-1 \mathrm{~g}$, due to the adverse pressure gradient, the $\mathrm{V}$ profile has features of a divergent flow. In $\mu \mathrm{g}$, the $\mathrm{V}$ profiles show that the $\mu \mathrm{g}$ had moved outside the measurement domain and truncated where $\mathrm{V}$ is still increasing. Therefore, the $\mu \mathrm{g}$ flame spreads further away from the centerline than the $+1 \mathrm{~g}$ flame. But more importantly, the absence of buoyancy forces yields a central products region $(\mathrm{y}<14 \mathrm{~mm})$ where $\mathrm{V}$ remains zero. The formation of a parallel flow at the center of the $\mu \mathrm{g}$ turbulent $\mathrm{V}$-flame is a compelling evidence to show that the convergent and divergent flow regions formed respectively in the plumes of $+1 \mathrm{~g}$ and $-1 \mathrm{~g}$ flames are direct consequences of buoyancy forces. Therefore, gravity effects can be significant in determining the mean strain rates and flame location in the farfield even when the nearfield is momentum dominant.

The u' and v' profiles shown in Figures 13 (c) and (d) provide more evidence on the preferential contributions of buoyancy to velocity fluctuations. In Fig 13(c), the u' levels in the center regions $(y<10 \mathrm{~mm})$ of the two buoyant flames are slightly higher than in the $\mu \mathrm{g}$ flame. From Figure 11 (c), it can be seen that the differences grow even larger downstream of this position. In comparison, the v' profiles 
of the three flames are comparable in the center region showing again that the unstable plumes generates flow fluctuations only in the axial direction. Therefore, the anisotropic turbulence found in the products region of laboratory v-flames is due to flow instabilities associated with the buoyant plume.

\section{Deviations from $2 D$ characteristics}

The significant flow divergence found in the $-1 \mathrm{~g}$ flames strongly suggests that they may no longer be strictly two dimensional. Without confinement, there should also be flow diverging out between the two flame sheets above the positions where the rod stabilizer intersect the burner rim. Measurements of the velocity statistics on the $\mathrm{x}-\mathrm{z}$ plane were carried out to characterize the extent of this outflow. Shown in Figure 14 is a comparison of the mean $\mathrm{x}-\mathrm{z}$ velocity vectors in $+1 \mathrm{~g}$ and $-1 \mathrm{~g}$ TVF1065. The outflows are shown by the vectors and by the contours of $|\mathrm{W}|$. The most surprising result is that both $+1 \mathrm{~g}$ and $-1 \mathrm{~g}$ have appreciable outflows. From the velocity vectors, the outflows escaping from the side boundaries of the $+1 \mathrm{~g}$ and $-1 \mathrm{~g}$ flames are calculated to be $38 \%$ and $43 \%$ respectively. Moreover, as shown by the $|\mathrm{w}|$ contours, the outflow velocities in both cases are higher in the nearfield than in the farfield. As this is a condition with relatively high Re and heat release, the outflows found in the nearfield regions below $|\mathrm{x}|=40 \mathrm{~mm}$ are most likely generated by gas expansion. Therefore, buoyancy has only a secondary influence on the outflows but is expected to become more dominant in the farfield.

To quantify if there is a significant change in the outflow with $\mathrm{Ri}$, we compare the $\mathrm{W}$ profiles measured at $|x|=13 \mathrm{~mm}$ (Figure 15). This is the position just downstream of the stabilizer rod and from the $x-y$ velocity vectors (e.g., Figures 2 and 3); flows in this nearfield region appear to be relatively free of buoyancy influences. In Figure 15 (a) for $+1 \mathrm{~g}$ laminar flames, all the profiles are linear and an increase in the outflow with decreasing $R i$ is clearly seen by the divergence rate $d W / d z$ increasing from $0.5 \mathrm{sec}^{-1}$ at $R i$ $=1.34$ (LVF0270) to $4.5 \mathrm{sec}^{-1}$ at $R i=0.08$ (LVF0870). This increase, however, it is almost linearly proportional to Re but has no linear relationship to Ri. For the -1g laminar flames (Figure 15 (b)), the W profiles are also linear for all cases. But there is a substantial increase in the divergence rate especially at high Ri. For LVF0270, reversing the flame increases $d W / d z$ from $0.5 \mathrm{sec}^{-1}$ to $4.6 \mathrm{sec}^{-1}$ whereas $d W / d z$ for LVF0870 experiences only a modest increase from $4.5 \mathrm{sec}^{-1}$ to $5.6 \mathrm{sec}^{-1}$. These results show that buoyancy contributions to the outflows are significant only for flames with low heat release rates and $R i>>0.1$.

For the turbulent flames, the $\mathrm{W}$ profiles show divergent trends but the profiles are linear only for some of the $+1 \mathrm{~g}$ flames. In Figure 15 (c), the W profiles for TVF0665 and TVF0865 are linear. The divergence rates of $3.4 \mathrm{sec}^{-1}$ and $4.4 \mathrm{sec}^{-1}$ respectively are comparable to those measured in LVF0670 $\left(3.9 \mathrm{sec}^{-1}\right)$ and LVF0870 $\left(4.6 \mathrm{sec}^{-1}\right)$. Taking into consideration that the turbulent flames are weaker with a lower $\phi$, these results show that turbulence does not alter the outflow and lends further support to the notion that the outflow is an attribute of heat release. Also shown in Figure 15 (c) is the W profile obtained in $\mu \mathrm{g}$ 
TVF0975. Though this flame has a higher $\phi$ and the profiles was measured at $|x|=20 \mathrm{~mm}$, the divergent rate is comparable to those of the $+1 \mathrm{~g}$ flame. The $\mathrm{W}$ profiles for the $-1 \mathrm{~g}$ turbulent flames in Figure 15 (d) all have a divergence trend but the data points are quite scattered. The mean divergence rate obtained from fitting these profiles results in $d W / d z$ of 5.1, 5.3, and $6 \mathrm{sec}^{-1}$ respectively for TVF0665, TVF0865 and TVF1065. These values are slightly higher then in the corresponding $+1 \mathrm{~g}$ flames and show weak buoyancy dependence. As previous OH-PLIF images has shown an in crease in flame wrinkling in the nearfield regions of $-1 \mathrm{~g}$ turbulent $\mathrm{v}$-flames, the slight increase in outflow seems to be associated with this phenomenon. These results clearly show that the outflows found in v-flames are non-trivial compared to the axial flow and they will certainly affect the distribution of velocities in the products. The most significant impact on our study and other studies using v-flames is that a simple 2D flame assumption cannot be invoked to assist in the interpretation of the experimental measurements.

\section{Discussion and Implications on Theories and Numerical Simulations}

This investigation together with our previous study have shown that buoyancy has significant influences on both the scalar and velocity fields of laminar and turbulent v-flames and the Richardson number $<0.1$ criterion is not adequate to prescribe a limit at which these influences would be overwhelmed by flow momentum. Most of the phenomena influenced by buoyancy i.e. degree of flame wrinkling, changes in flow acceleration and turbulence production, undergo quite subtle changes due to their close coupling with other flame flow interaction processes. Consequently, buoyancy contributions are not easily and readily identifiable. But they cannot be ignored in fundamental studies or else the conclusions and insights would be ambiguous and not very meaningful.

Our experimental observations have significant implications on the extent to which different theoretical models and numerical simulations can consider the field effects of buoyancy. Until recent development of 2D and 3D simulations, experimental measurements have been used mostly to assist in the development of second order closure methods for 1D flame models (e.g. Bray-Moss-Libby model [13] ). By virtue of the $1 \mathrm{D}$ assumption, BML type models cannot be generalized for most flame configurations but the empirical constants used in the closure models can be configuration or flowfield specific. As buoyancy affects the phenomena that are being modeled i.e. flame wrinkling (crossing frequencies and flame surface density) and velocity jumps (counter-gradient diffusion), buoyancy contributions may be included implicitly in the empirical constants through measurements of these parameters in $+1 \mathrm{~g},-1 \mathrm{~g}$ and $\mu \mathrm{g}$ flames.

In $2 \mathrm{D}$ discrete random vortex dynamic simulation of time-dependent flowfields of premixed turbulent flames, the wrinkled flame fronts are represented by a set of marker particles $[10,14]$ or by the level set 
algorithm [15]. Exothermic volume generation, baroclinic vorticity generation and flame generated acceleration and their combined effects on the overall flame dynamics can be modeled using source terms at the flame fronts. Unlike BML model, vortex dynamic simulations apply to different flow and burner configurations. They calculate directly the evolutions in flame wrinkle formation and the flame-generated velocity and vorticity fields and handle some aspects of the pressure field (e.g., baroclinicity). Therefore, they can be further developed to consider buoyancy effects on the mean flow, flame wrinkling, and turbulent transports. However, these are strictly 2D simulations and the experiments to support the development of these simulations need to be carefully designed to avoid the type of outflows that exists in our current v-flame system.

In Direct-Numerical-Simulation (DNS) of turbulent combustion, all turbulence and flame scales can be resolved without the need for extensive modeling $[16,17]$. DNS calculations tend to cover relatively small physical domains (typically no larger than $2-3 \mathrm{~cm}^{3}$ ) with very fine scale uniform mesh. Both 2D and 3D DNS calculations are now available for unsteady lean premixed turbulent flames. DNS is particularly useful for the analysis of local turbulence/flame processes to examine the higher order terms in the transport equations for the Reynolds stresses, turbulent scalar fluxes and flame surface density. As our experimental data have shown, all these quantities have direct relevance to buoyancy contributions. However, the computational domain of DNS is not sufficiently large and the calculations need to be embedded into a flowfield model such as the Large Eddy-Simulation (LES) [18, 19]. Therefore, successes in simulating the buoyancy contributions rest largely on how LES generate the boundary conditions for the DNS subscale models.

The availability of super computers coupled with parallel processing technologies had accelerated the development of time-dependent 3D models that simulate the entire flowfields of steady turbulent premixed flames. Bell et al [20] have developed methods to resolve turbulent combustion problems using discretization methodology for low Mach number flows based on compressible second order NavierStokes equations. An especially useful tool, adaptive mesh refinement (AMR), is one of the major areas of research. AMR works by dividing the flowfield into smaller parts. Areas of interest such as the flame zones are treated with successively finer meshes to provide more detailed information. This approach allows the treatment of complex flows in different burner geometries with detailed chemistry. Using AMR method, Bell et al. [21] recently simulated in 3D a buoyant premixed turbulent v-flame. The configuration is similar to the one studied here but the burner is twice as large with an exit diameter of $5 \mathrm{~cm}$. The simulation domain is approximately $10 \mathrm{~cm}^{3}$ and preliminary comparison with experimental measurements show that the calculation captures the essential overall features of the flame such as growth of the flame brush thickness and the flame angles. Qualitative comparison between the experimental and 
simulated velocity statistics obtained on the $x-y$ and the $x-z$ plane are being carried out. These results are very encouraging and show that the numerical simulation using AMR can be a very useful tool for investigating buoyancy effects. Because buoyancy contribution is a constant in this simulation, it can be switch on or off to test the fidelity of this method in handling pressure feedback problems. Because AMR simulations predict detailed flow and scalar statistics, our experimental data are well suited to provide different levels of validation for this promising numerical method.

\section{Conclusions}

The field effects of buoyancy on laminar and turbulent premixed v-flames have been studied by the use of laser Doppler velocimetry to characterize the flowfields of flames subjected to $+1 \mathrm{~g},-1 \mathrm{~g}$ and $\mu \mathrm{g}$ environments. In the laboratory, extensive measurements of the velocity statistics in $+1 \mathrm{~g}$ and $-1 \mathrm{~g}$ flames were obtained by scanning these flames along streamlines and the centerline as well as cross stream traverses in two directions perpendicular $(x-y)$ and parallel $(x-z)$ to the flame stabilizer rod. The measurement domains extend into the farfield to show the flowfield evolution in the buoyant plume. For the $\mu \mathrm{g}$ experiments, due to the limited duration of $\mu \mathrm{g}$ environment in parabolic flights, axial and cross stream profiles at selected locations on the $x-y$ and $x-z$ plane were obtained. The experimental conditions cover mean exit velocity, $U_{0}$, of 0.4 to $2 \mathrm{~m} / \mathrm{s}$, methane/air equivalence ratio, $\phi$, of 0.62 to 0.75 , Reynolds numbers, $R e$, from 625 to 3130 and Richardson number, $R i$, from 0.05 to 1.34 .

Comparison of the velocity vectors on the $\mathrm{x}-\mathrm{y}$ plane of $+1 \mathrm{~g}$ and $-1 \mathrm{~g}$ laminar flames at $\mathrm{Ri}=0.34$ shows that a change in the mean pressure gradient in the plume from favorable $(+1 \mathrm{~g})$ to unfavorable $(-1 \mathrm{~g})$ creates a stagnating flow in the farfield. This causes the flame sheet to curl and deflects the flow of the reactants outwards to form large recirculation regions at the top edges of the flame sheets. In contrast, the flowfield of the $+1 \mathrm{~g}$ laminar flame has a plume that is convergent and accelerating. For turbulent flames at $R i=0.053$, the stagnating flow in $-1 \mathrm{~g}$ is formed further downstream. In the nearfield, the differences between the $+1 \mathrm{~g}$ and $-1 \mathrm{~g}$ flames are less apparent. But in the farfield, flow divergence and the generation of a side recirculation remain the key flowfield features of the $-1 \mathrm{~g}$ turbulent $\mathrm{v}$-flame.

The mean streamlines were used to investigate how the buoyancy effects on the flowfields evolve with increasing flow momentum. Ten sets of $+1 \mathrm{~g}$ and $-\mathrm{g}$ laminar $(0.08<R e<1.34)$ and turbulent $(0.05<R i<$ 0.15 ) flames had been compared. For the laminar flames, buoyancy domination in the flowfield are shown by the $-1 \mathrm{~g}$ streamlines all having higher degrees of outward flow deflection in the reactants and continuous diverging trends in the products. This shows a persistent effect of buoyancy in the nearfield even at $R i=0.08$. Therefore, the use of Richardson number $<0.1$ as a criterion for momentum dominance is not adequate to prescribe the field effects of buoyancy. In the turbulent flames, the $+1 \mathrm{~g}$ and $-1 \mathrm{~g}$ 
streamlines are not very different even for those cases with similar Richardson numbers as the laminar flames $(0.08<R e<0.3)$. This indicates that the steering of the mean flow direction is no longer the main manifestation of buoyancy effects when turbulence is present. The mean and rms velocity profiles along the streamline show this to be the case where the mean flow speed and rms velocities of the $+1 \mathrm{~g}$ and $-1 \mathrm{~g}$ turbulent flames are different within the reactants upstream of the turbulent flame brush as well as in the plumes.

Non-buoyant flames were studied by measuring the velocity statistics of a $\mu \mathrm{g}$ laminar and a $\mu \mathrm{g}$ turbulent flame generated on board an aircraft flying in parabolic trajectories. Profiles along the centerline and two cross-stream traverses were obtained and compared with the corresponding laboratory $+1 \mathrm{~g}$ and $-1 \mathrm{~g}$ flames. For the $\mu \mathrm{g}$ laminar flames, flow acceleration and fluctuations are absent within its plume. The natural convection velocity gave a fair approximation of the differences between the mean centerline flow velocities of the $+1 \mathrm{~g}$ and $\mu \mathrm{g}$ flames but failed to approximate the difference between the $-1 \mathrm{~g}$ and $\mu \mathrm{g}$ flames. Without buoyancy, the plume of the $\mu \mathrm{g}$ flame remained laminar and proved that the increases in rms velocities in the plumes of $+1 \mathrm{~g}$ and $-1 \mathrm{~g}$ flames are generated by the buoyant unstable plumes. The transverse profiles show that $\mu$ g flame has a central products region where the flow remained parallel. Therefore, the convergent and divergent regions formed respectively in the plumes of $+1 \mathrm{~g}$ and $-1 \mathrm{~g}$ flames are also direct consequences of buoyancy forces. The comparison of the profiles obtained in the $+1 \mathrm{~g},-1 \mathrm{~g}$ and $\mu \mathrm{g}$ turbulent flames produced similar conclusion. In addition, they show that the turbulence in the plume regions of $+1 \mathrm{~g}$ v-flames is anisotropic due to the buoyant unstable plumes.

Measurements of the velocity statistics on the $x-z$ plane were carried out to characterize the divergence of products flowing out between the two flame sheet above the positions where the stabilizer rod intersects the burner rim. Data from $+1 \mathrm{~g},-1 \mathrm{~g}$ and $\mu \mathrm{g}$ laminar and turbulent flames clearly show that the outflows in v-flames are non-trivial compared to the axial flow but their magnitudes are not sensitive to buoyancy. The most significant impact on our study and other studies using v-flames is that a simple 2D flame assumption cannot be invoked to assist in the interpretation of the experimental measurements.

This investigation and our previous study show that buoyancy has significant influences on both the scalar and velocity fields of laminar and turbulent v-flames. Most of the phenomena influenced by buoyancy i.e. degree of flame wrinkling, flow acceleration, flow distribution, and turbulence production, undergo quite subtle changes due to their close coupling with other flame flow interaction processes. Consequently, buoyancy contributions are not easily and readily identifiable. Therefore, the $\mu \mathrm{g}$ experiments are essential to uncover these field effects. However, more detailed statistical data on conditional velocity statistics and flame wrinkle structures would be necessary to better characterize the upstream coupling mechanisms of buoyancy that affect local flame/turbulence processes as well as flame 
wrinkle structures. As computer simulations are advancing towards computing 3D flows and flame structures of buoyant and non-buoyant flames, these experimental measurements will be very useful to support and validate these numerical developments.

\section{Acknowledgement}

This work was supported by NASA Office of Biological and Physical Research under Contract No. C-32000-R through the U. S. Department of Energy Contract No. DE-AC03-76F00098. Additional research facility and equipment provided by U. S. Department of Energy, Office of Science. Technical support for the microgravity experiments was provided by NASA Glenn Research Center. The authors would like to thank Mr. Gary Hubbard for writing the computer-controlled software for the laboratory and aircraft experiments, the flight support team for the DC9 and KC135 aircrafts, and also the ground support team in Building 101 at NASA Glenn Research Center.

\section{References}

[1] G. K. Batchelor, An Introduction to FLuid Mechanics. University Press, Cambridge, 1977,

[2] B. Bedat and R. K. Cheng, Combustion and Flame, 107 (1-2) (1996) 13-26.

[3] R. K. Cheng and B. Bedat, Combustion and Flame, 116 (3) (1999) 360-375.

[4] R. K. Cheng, Combustion and Flame, 101 (1-2) (1995) 1-14.

[5] R. K. Cheng and T. T. Ng, Combustion and Flame, 52 ((1983) 185-202.

[6] R. K. Cheng and I. G. Shepherd, Combustion and Flame, 85 (1-2) (1991) 7-26.

[7] R. K. Cheng, I. G. Shepherd and L. Talbot, Int'l. Comb. Sym., 22 ((1988) 771.

[8] L. W. Kostiuk and R. K. Cheng, Combustion and Flame, 103 (1-2) (1995) 27-40.

[9] L. W. Kostiuk and R. K. Cheng, Experiments in Fluids, 18 (1-2) (1994) 59-68.

[10] M. Z. Pindera and L. Talbot, Combustion and Flame, 73 (2) (1988) 111-125.

[11] J. O. Sinibaldi, C. J. Mueller, A. Tulkki and J. F. Driscoll, AIAA J., 36 (8) (1998) 1432-1438.

[12] R. K. Cheng, L. Talbot and F. Robben, 20th Int'l. Sym. on Combustion, The Combustion Instittue, Pittsburgh, 1984, 453.

[13] K. N. C. Bray, P. A. Libby and J. B. Moss, Combustion and Flame, 61 (1) (1985) 87-102.

[14] M. Z. Pindera and L. Talbot, Twenty-First Symposium (International) on Combustion, The Combustion Institute, Pittsburgh, 1986, 1231-1250.

[15] C. W. Rhee, L. Talbot and J. A. Sethian, J. Fluid Mech., 300 ((1995) 87-115.

[16] T. Poinsot, S. Candel and A. Trouve, Progress in Energy and Combustion Science, 21 (6) (1995) 531-576.

[17] T. J. Poinsot, D. C. Haworth and G. Bruneaux, Combustion and Flame, 95 (1-2) (1993) 118-132.

[18] E. R. Hawkes and R. S. Cant, Proceedings of the Combustion Institute, 28 (1) (2000) 51-58. 
[19] E. R. Hawkes and R. S. Cant, Combustion and Flame, 126 (3) (2001) 1617-1629.

[20] J. B. Bell, M. S. Day, J. F. Grcar and M. J. Lijewski, Proc. Comb. Inst., 29 ((2002)

[21] J. B. Bell, M. S. Day, J. F. Grcar, M. J. Lijewski, R. K. Cheng and I. G. Shepherd, 19th International Colloquium on the Dynamics of Explosion and Reactive Systems, Hakone, Japan, 2003. Also at http://seesar.lbl.gov/CCSE/Research/Combustion/V-flames.html 
Table I - Laminar Flame Experiments:

\begin{tabular}{|c|c|c|c|c|c|c|c|c|c|}
\hline Flame & $\begin{array}{l}\mathrm{Q} \\
1 / \mathrm{s}\end{array}$ & $\begin{array}{c}\mathrm{U}_{\infty} \\
\mathrm{m} / \mathrm{s}\end{array}$ & $\operatorname{Re}$ & $\bar{\phi}$ & $\mathrm{Ri}$ & $\begin{array}{c}\text { Heat } \\
\text { release } \\
\mathrm{kW}\end{array}$ & $+1 \mathrm{~g}$ data & $-1 \mathrm{~g}$ data & $\mu \mathrm{g}$ data \\
\hline LVF0270 & 0.20 & 0.39 & 625 & 0.70 & 1.34 & 0.54 & $\mathrm{~S}_{1}, \mathrm{~S}_{2,} \mathrm{Z}_{13}$ & $\mathrm{~S}_{1}, \mathrm{~S}_{2, \mathrm{Z}_{13}}$ & \\
\hline LVF0470 & 0.40 & 0.79 & 1250 & 0.70 & 0.335 & 1.1 & $\mathrm{~S}_{1}, \mathrm{~S}_{2,} \mathrm{Z}_{13, \mathrm{X}-\mathrm{y}}$ & $\mathrm{S}_{1}, \mathrm{~S}_{2, \mathrm{Z}} \mathrm{Z}_{13, \mathrm{X}-\mathrm{y}}$ & \\
\hline LVF0670 & 0.60 & 1.18 & 1880 & 0.70 & 0.15 & 1.63 & $\begin{array}{l}\mathrm{S}_{1}, \mathrm{~S}_{2,} \mathrm{x}_{0}, \mathrm{y}_{20} \\
\mathrm{y}_{40}, \mathrm{z}_{13}\end{array}$ & $\begin{array}{l}\mathrm{S}_{1}, \mathrm{~S}_{2,} \mathrm{x}_{0}, \mathrm{y}_{20} \\
\mathrm{y}_{40}, \mathrm{z}_{13}\end{array}$ & $\mathrm{x}_{0}, \mathrm{y}_{20}, \mathrm{y}_{40}$ \\
\hline LVF0870 & 0.80 & 1.58 & 2500 & 0.70 & 0.084 & 2.17 & $\mathrm{~S}_{1}, \mathrm{~S}_{2,} \mathrm{Z}_{13}$ & $\mathrm{~S}_{1}, \mathrm{~S}_{2,} \mathrm{Z}_{13}$ & \\
\hline
\end{tabular}

Table II - Turbulent Flame Experiments:

\begin{tabular}{|c|c|c|c|c|c|c|c|c|c|}
\hline Flame & $\begin{array}{l}\mathrm{Q} \\
1 / \mathrm{s}\end{array}$ & $\begin{array}{l}\mathrm{U}_{\infty} \\
\mathrm{m} / \mathrm{s}\end{array}$ & $\overline{\mathrm{Re}}$ & $\overline{\phi \phi}$ & $\overline{\mathrm{Ri}}$ & $\begin{array}{c}\text { Heat } \\
\text { release } \\
\mathrm{kW}\end{array}$ & +1g data & $-1 \mathrm{~g}$ data & $\overline{\mu g \mathrm{~g} \text { data }}$ \\
\hline TVF0662 & 0.60 & 1.18 & 1880 & 0.62 & 0.147 & 1.45 & $\mathrm{~S}_{1}, \mathrm{~S}_{2}$ & $\mathrm{~S}_{1}, \mathrm{~S}_{2}$ & \\
\hline TVF0862 & 0.80 & 1.58 & 2500 & 0.62 & 0.083 & 1.95 & $\mathrm{~S}_{1}, \mathrm{~S}_{2}$ & $\mathrm{~S}_{1}, \mathrm{~S}_{2}$ & \\
\hline \begin{tabular}{|l|} 
TVF1062 \\
\end{tabular} & 1.00 & 1.97 & 3130 & 0.62 & 0.053 & 2.43 & $\mathrm{~S}_{1}, \mathrm{~S}_{2}$ & $\mathrm{~S}_{1}, \mathrm{~S}_{2}$ & \\
\hline TVF0665 & 0.60 & 1.18 & 1880 & 0.65 & 0.148 & 1.52 & $\mathrm{~S}_{1}, \mathrm{~S}_{2, \mathrm{Z}_{13}}$ & $\mathrm{~S}_{1}, \mathrm{~S}_{2,} \mathrm{Z}_{13}$ & \\
\hline \begin{tabular}{|l|} 
TVF0865 \\
\end{tabular} & 0.80 & 1.58 & 2500 & 0.65 & 0.083 & 2.03 & $\mathrm{~S}_{1}, \mathrm{~S}_{2, \mathrm{Z}_{13}}$ & $\mathrm{~S}_{1}, \mathrm{~S}_{2, \mathrm{Z}_{13}}$ & $\mathrm{x}_{0}$ \\
\hline TVF1065 & 1.00 & 1.97 & 3130 & 0.65 & 0.053 & 2.54 & $\begin{array}{l}\mathrm{S}_{1}, \mathrm{~S}_{2,} \mathrm{Z}_{13}, \mathrm{x}- \\
\mathrm{y}, \mathrm{x}-\mathrm{z}\end{array}$ & $\begin{array}{l}\mathrm{S}_{1}, \mathrm{~S}_{2,} \mathrm{Z}_{13}, \mathrm{x}- \\
\mathrm{y}, \mathrm{x}-\mathrm{z}\end{array}$ & \\
\hline \begin{tabular}{|l|} 
TVF0975 \\
\end{tabular} & 0.9 & 1.78 & 2820 & 0.75 & 0.066 & 2.62 & $\mathrm{y}_{20}, \mathrm{y}_{40}, \mathrm{x}_{0}$ & $\mathrm{y}_{20}, \mathrm{y}_{40}, \mathrm{x}_{0}$ & $\begin{array}{l}\mathrm{y}_{20}, \mathrm{y}_{40}, \mathrm{x}_{0}, \\
\mathrm{z}_{20}\end{array}$ \\
\hline
\end{tabular}

Key to Table I\&II

$\mathrm{S}_{1} \quad$ Inner streamline starting at $|\mathrm{x}|=6 \mathrm{~mm}, \mathrm{y}=4 \mathrm{~mm}$

$\mathrm{S}_{2} \quad$ Outer streamline starting at $|\mathrm{x}|=6 \mathrm{~mm}, \mathrm{y}=7 \mathrm{~mm}$

$\mathrm{x}_{0} \quad$ Centerline axial traverse on the $\mathrm{x}-\mathrm{y}$ plane at $\mathrm{y}=0$

$\mathrm{y}_{20} \quad$ Cross-stream traverse on the $\mathrm{x}-\mathrm{y}$ plane at $|\mathrm{x}|=20 \mathrm{~mm}$

$\mathrm{y}_{40} \quad$ Cross-stream traverse on the $\mathrm{x}-\mathrm{y}$ plane at $|\mathrm{x}|=40 \mathrm{~mm}$

$\mathrm{z}_{13} \quad$ Cross-stream traverse on the $\mathrm{x}-\mathrm{z}$ plane at $|\mathrm{x}|=13 \mathrm{~mm}$

$\mathrm{Z}_{20} \quad$ Cross-stream traverse on the $\mathrm{x}-\mathrm{z}$ plane at $|\mathrm{x}|=20 \mathrm{~mm}$

$\mathrm{x}-\mathrm{y} \quad$ Mapping of the velocity vectors on the $\mathrm{x}-\mathrm{y}$ plane

$\mathrm{x}-\mathrm{z} \quad$ Mapping of the velocity vectors on the $\mathrm{x}-\mathrm{z}$ plane 


\section{Figure Captions:}

Figure $1 \quad$ Experimental apparatus for the parabolic flight experiments

Figure2 Mean velocity vectors and flow speed contour on the $x-y$ plane of $+1 g$ and $-1 \mathrm{~g}$ LVF0470

Figure 3 Mean velocity vectors and flow speed contour on the $x-y$ plane of $+1 g$ and $-1 \mathrm{~g}$ TVF1065

Figure 4 Comparison of streamline measured in $+1 \mathrm{~g}$ and $-1 \mathrm{~g}$ laminar $\mathrm{V}$-flames

Figure 5 Comparison of streamline measured in $+1 \mathrm{~g}$ and $-1 \mathrm{~g}$ turbulent $\mathrm{V}$-flames

Figure 6 Mean and rms velocity profiles along streamlines of $+1 \mathrm{~g}$ and $-1 \mathrm{~g}$ LVF0670

Figure 7 Mean and rms velocity profiles along streamlines of $+1 \mathrm{~g}$ and $-1 \mathrm{~g}$ TVF0665

Figure $8 \quad$ Mean and rms profiles on the centerline of $+1 \mathrm{~g},-1 \mathrm{~g}$ and $\mu \mathrm{g}$ LVF0670

Figure 9 Mean and rms profiles at $|\mathrm{x}|=20 \mathrm{~mm}$ in $+1 \mathrm{~g},-1 \mathrm{~g}$ and $\mu \mathrm{g}$ LVF0670

Figure $10 \quad$ Mean and rms profiles at $|\mathrm{x}|=40 \mathrm{~mm}$ in $+1 \mathrm{~g},-1 \mathrm{~g}$ and $\mu \mathrm{g}$ LVF0670

Figure $11 \quad$ Mean and rms profiles on the centerline of $+1 \mathrm{~g},-1 \mathrm{~g}$ and $\mu \mathrm{g}$ TVF0975

Figure 12 Mean and $\mathrm{rms}$ profiles at $|\mathrm{x}|=20 \mathrm{~mm}$ in $+1 \mathrm{~g},-1 \mathrm{~g}$ and $\mu \mathrm{g}$ TVF0975

Figure $13 \quad$ Mean and rms profiles at $|\mathrm{x}|=40 \mathrm{~mm}$ in $+1 \mathrm{~g},-1 \mathrm{~g}$ and $\mu \mathrm{g}$ TVF0975

Figure 14 Mean velocity vectors and $|\mathrm{W}|$ contour on the $\mathrm{x}-\mathrm{z}$ plane of $+1 \mathrm{~g}$ and $-1 \mathrm{~g}$ TVF1065

Figure $15 \quad$ Mean W profiles laminar and turbulent v-flames in $+1 \mathrm{~g}$ and $-1 \mathrm{~g}$. 


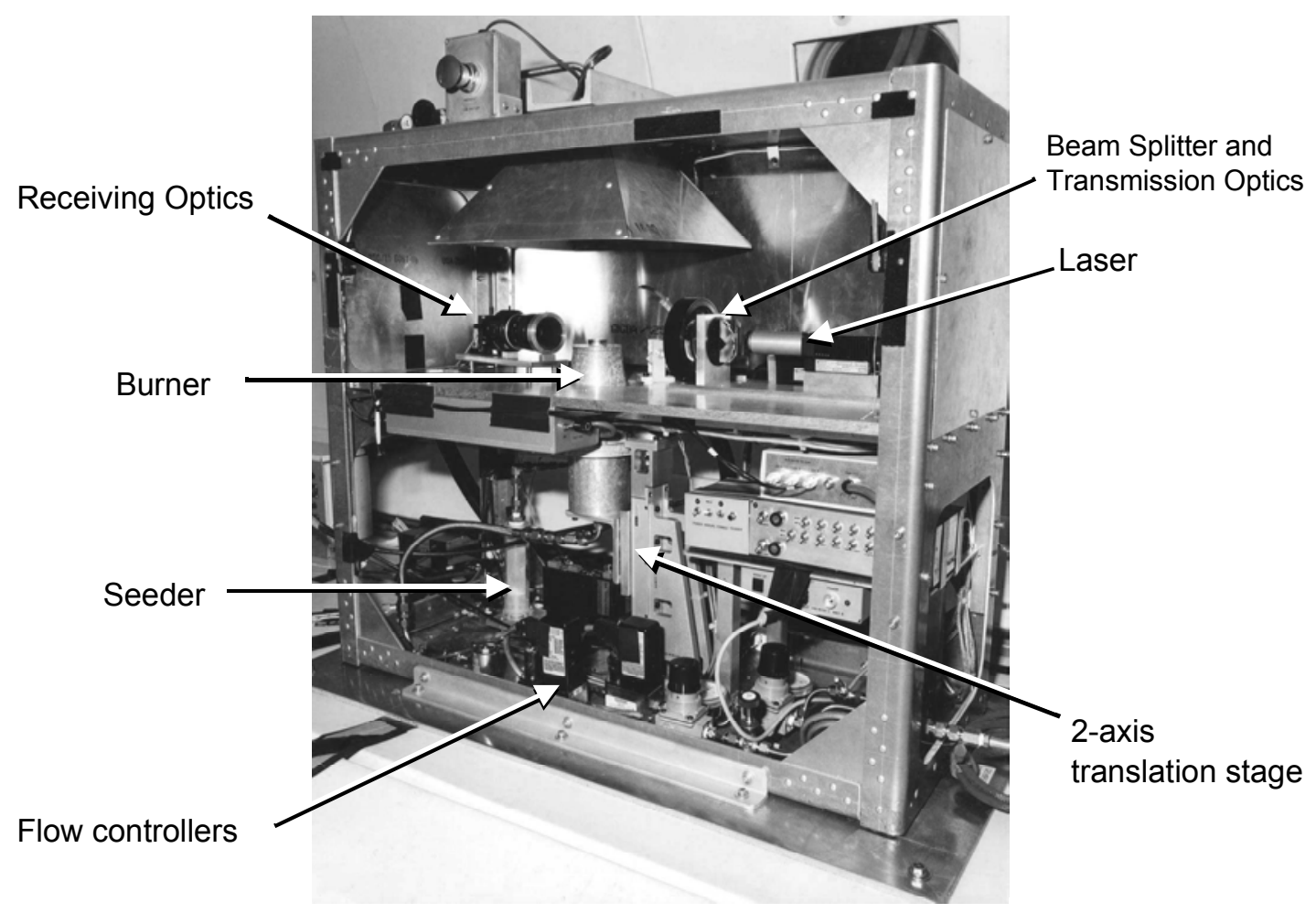

Figure 1 Experimental apparatus for the parabolic flight experiments 

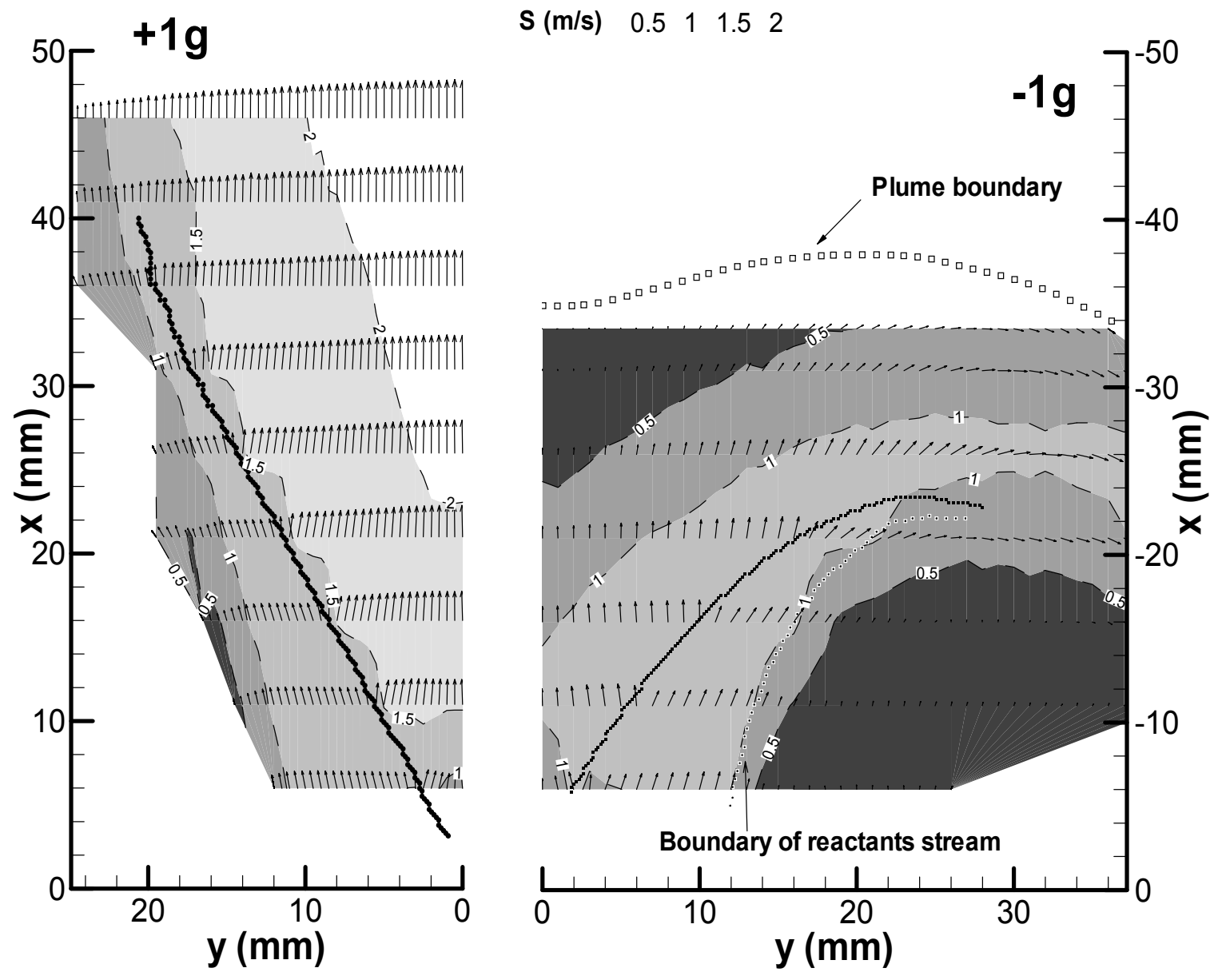

Figure 2 Mean velocity vectors and flow speed contour on the $x-y$ plane of $+1 \mathrm{~g}$ and $-1 \mathrm{~g}$ LVF0470 

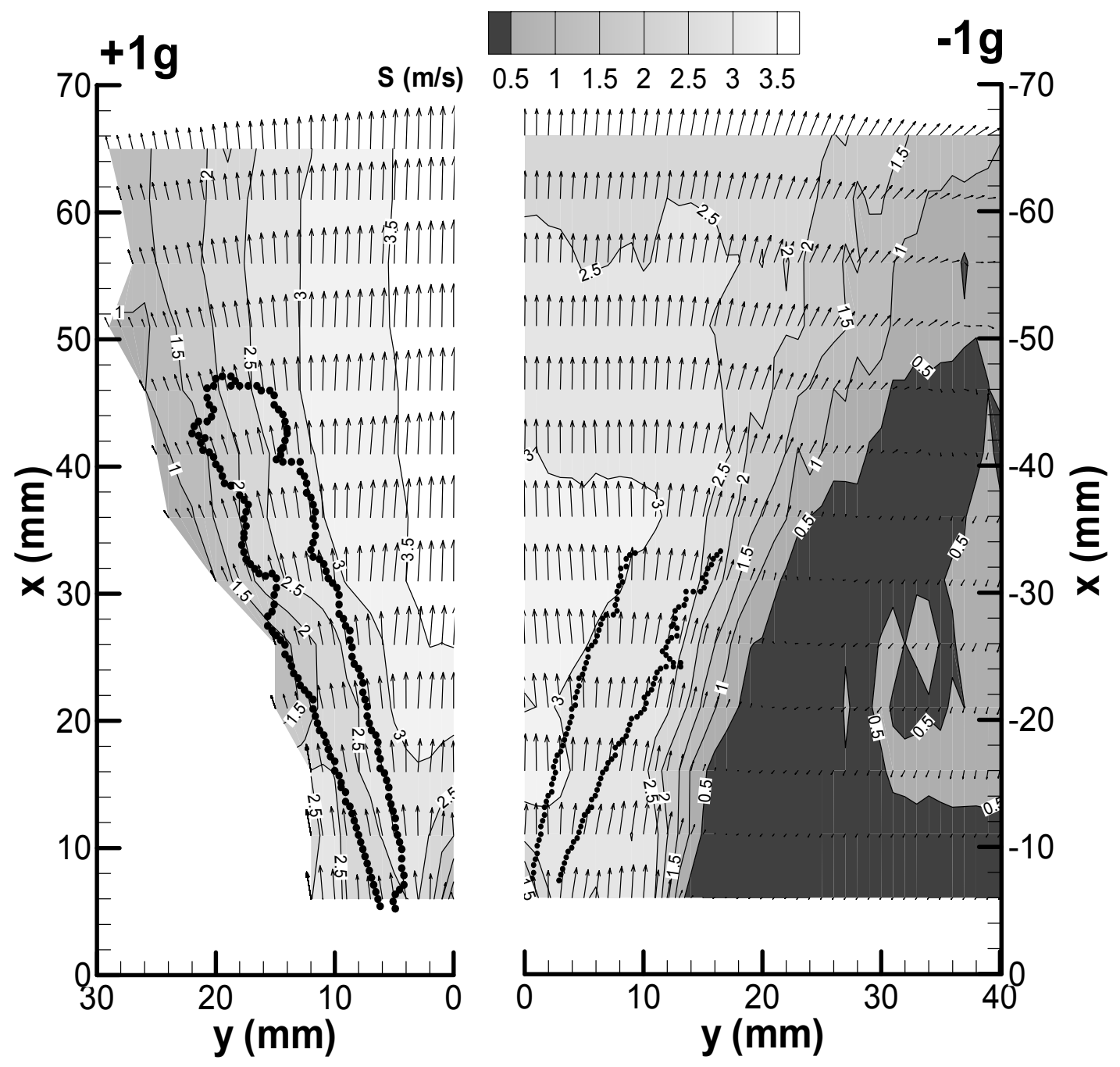

Figure 3 Mean velocity vectors and flow speed contour on the $x-y$ plane of $+1 g$ and $-1 \mathrm{~g}$ TVF1065 

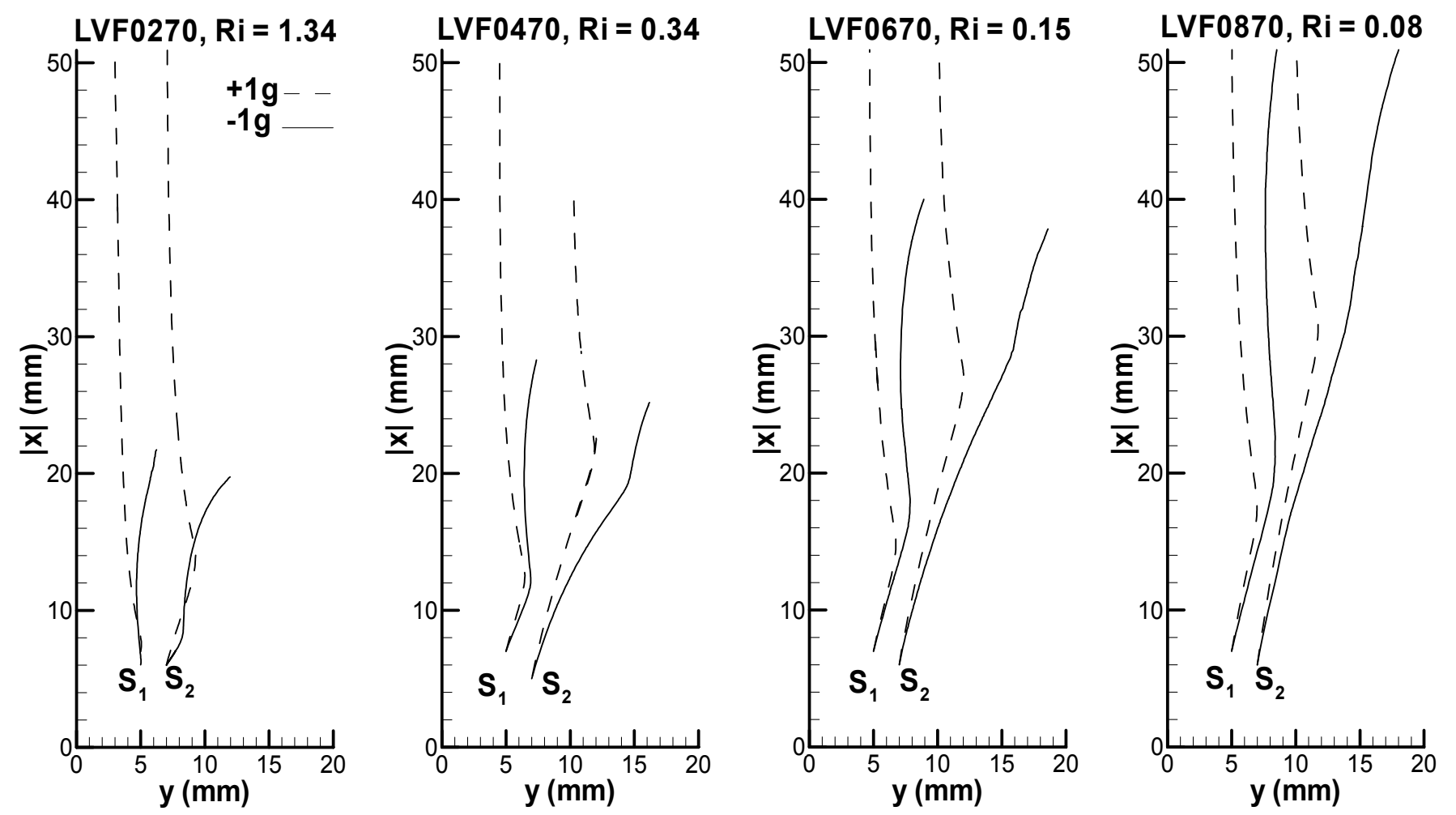

Figure 4 Comparison of streamline measured in $+1 \mathrm{~g}$ and $-1 \mathrm{~g}$ laminar V-flames 

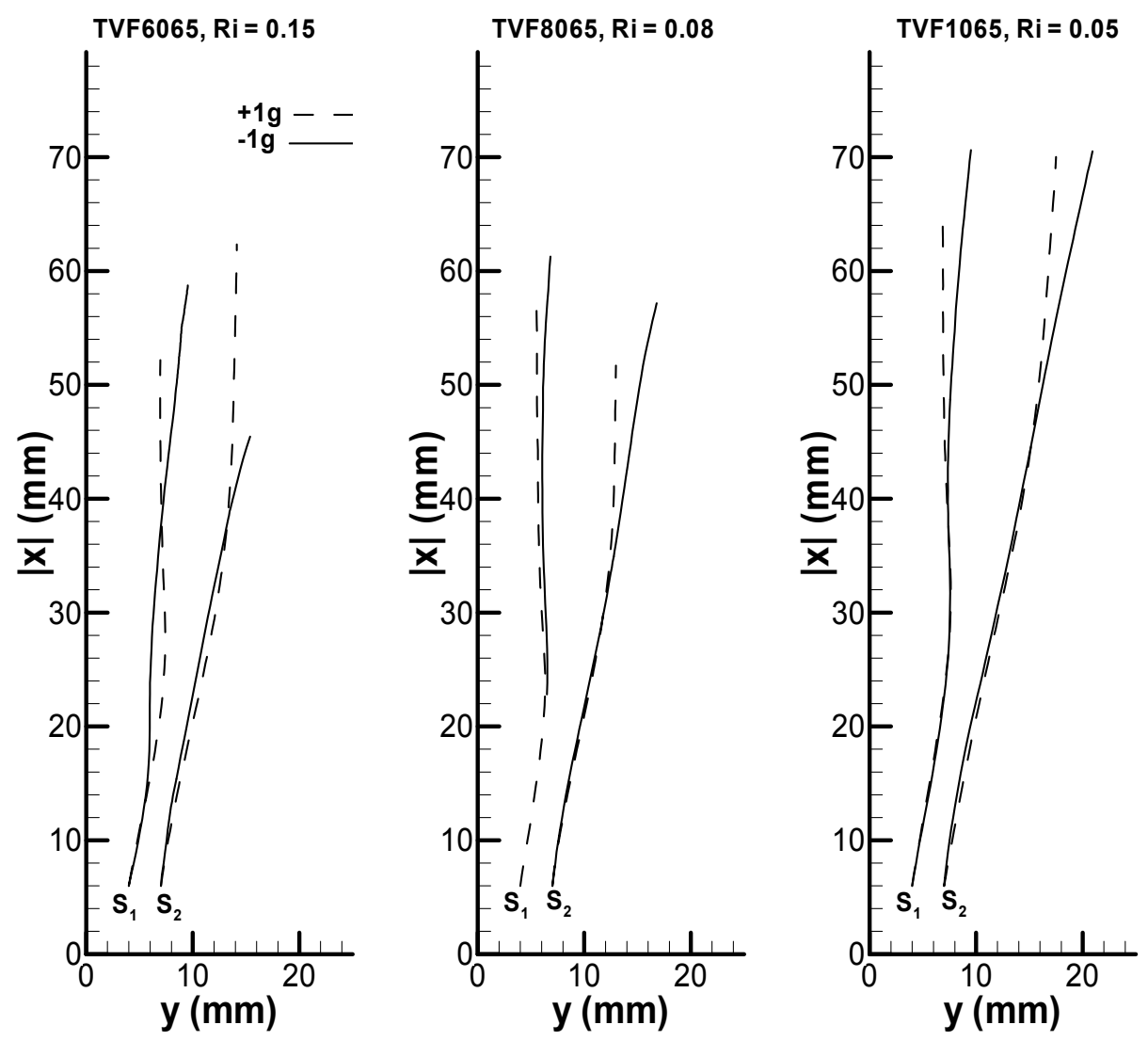

Figure 5 Comparison of streamline measured in $+1 \mathrm{~g}$ and $-1 \mathrm{~g}$ turbulent V-flames 

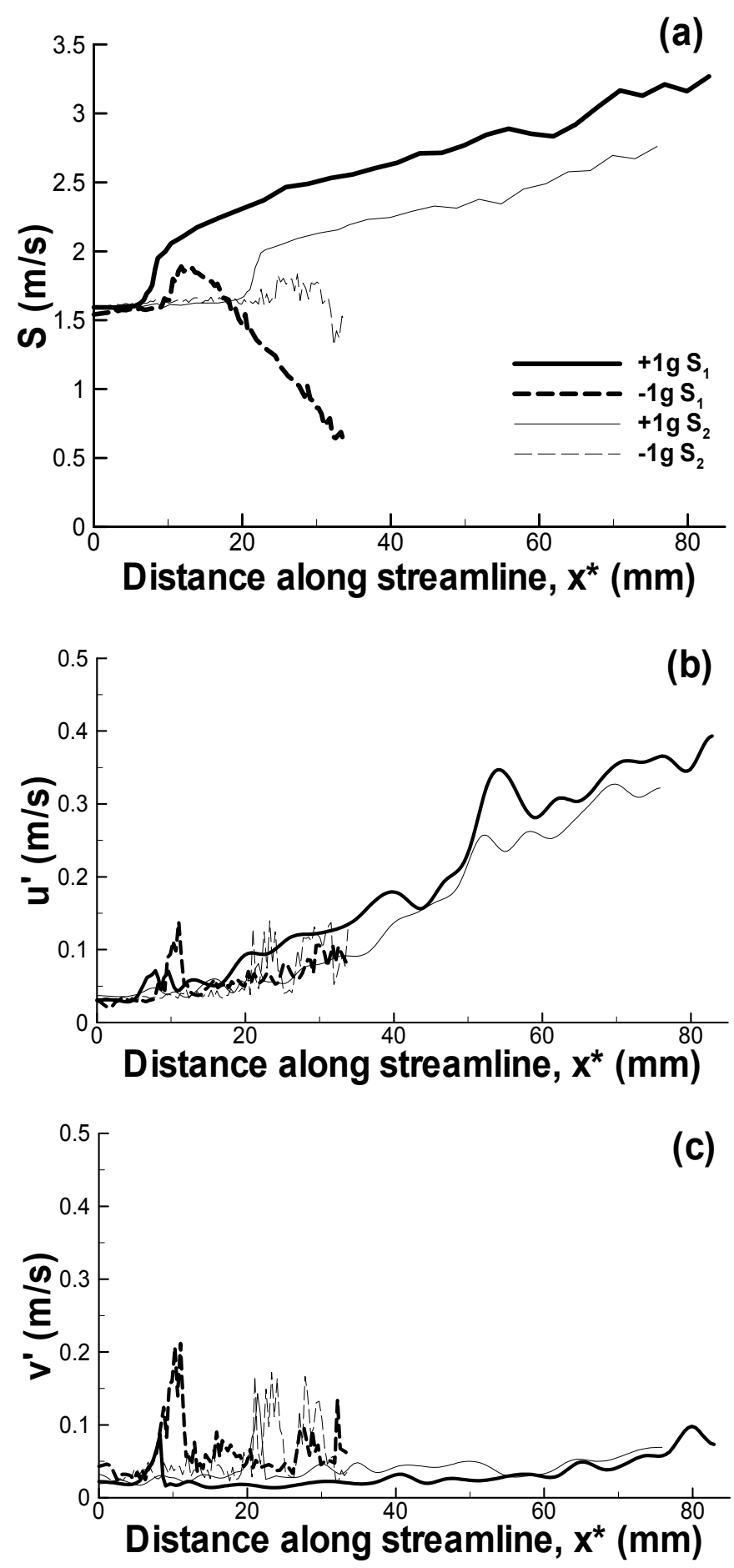

Figure 6 Mean and rms velocity profiles along streamlines of $+1 \mathrm{~g}$ and $-1 \mathrm{~g}$ LVF0670 

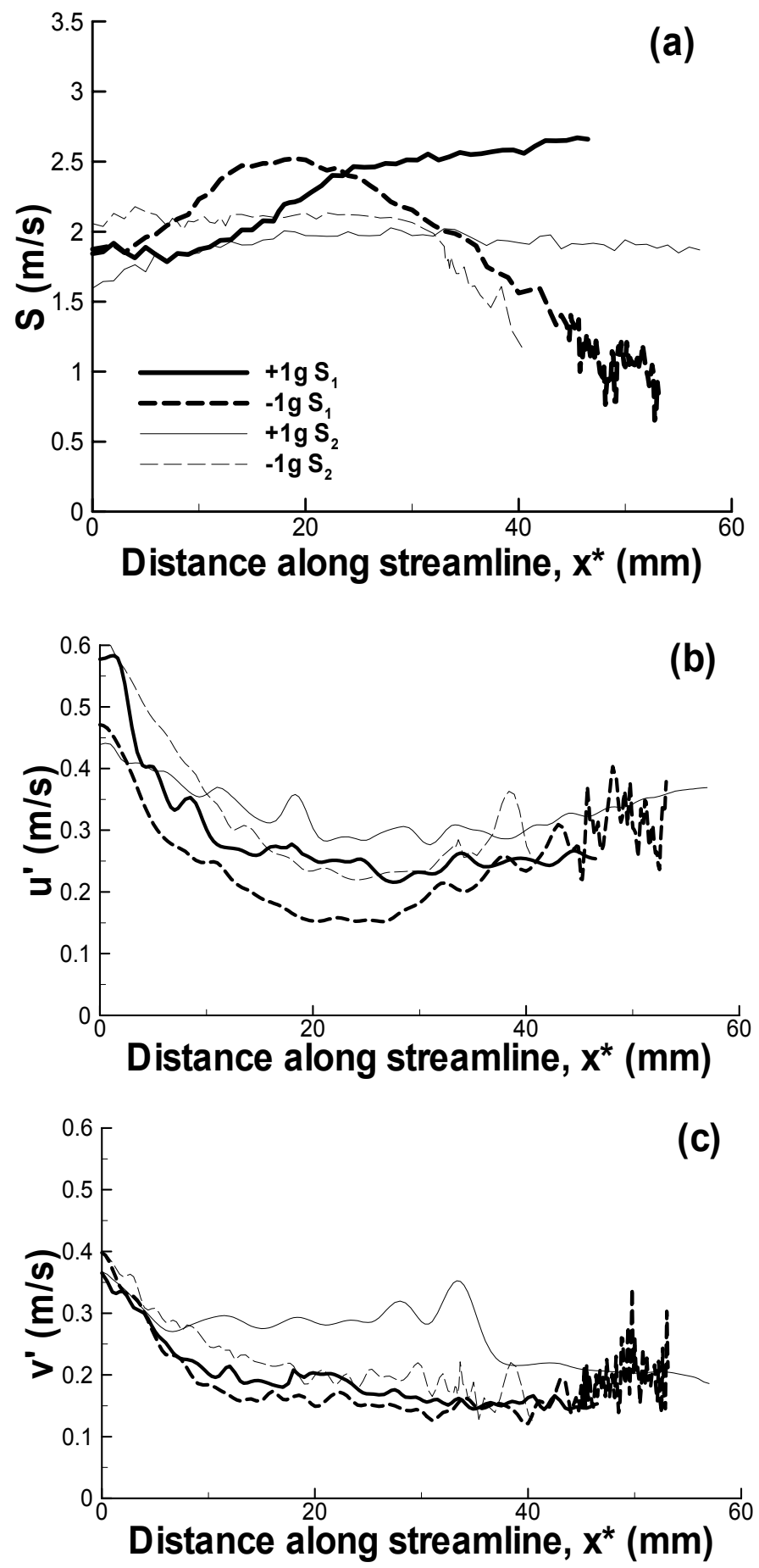

Figure 7 Mean and rms velocity profiles along streamlines of $+1 \mathrm{~g}$ and $-1 \mathrm{~g}$ TVF0665 

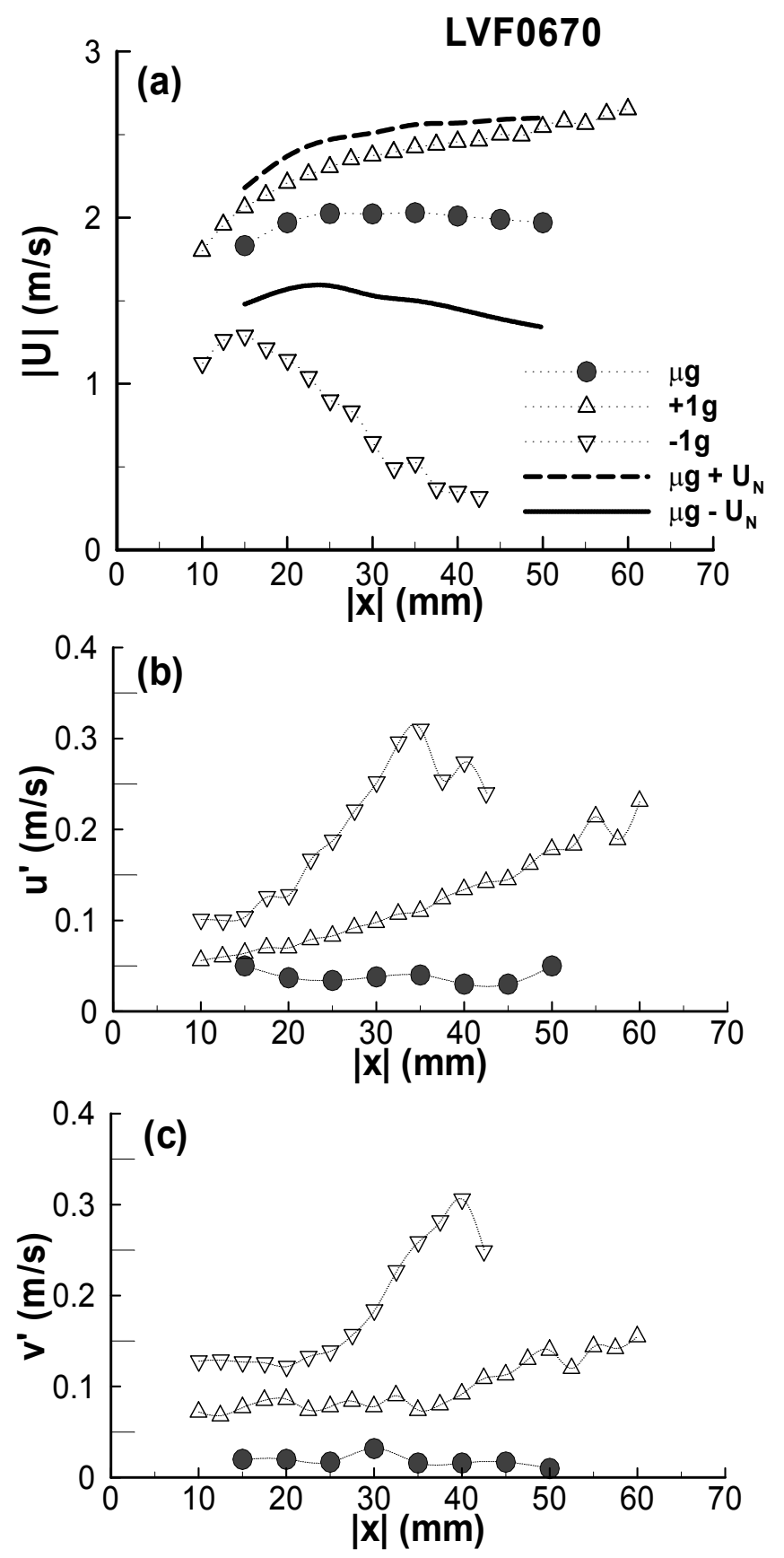

Figure 8 Mean and rms profiles on the centerline of $+1 \mathrm{~g},-1 \mathrm{~g}$ and $\mu \mathrm{g}$ LVF0670 

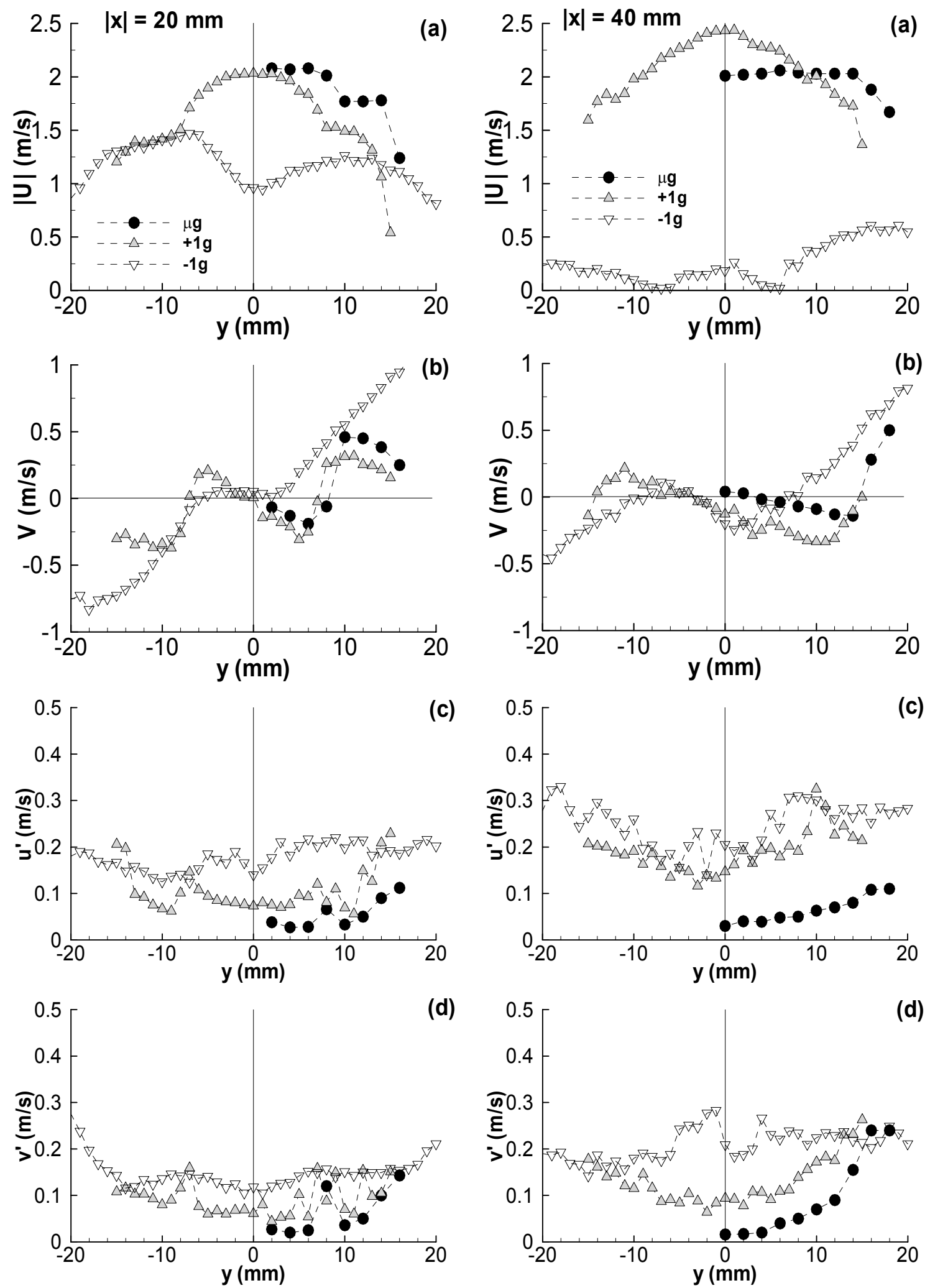

Figure 9 Mean and rms profiles at $|\mathrm{x}|=20$ $\mathrm{mm}$ in $+1 \mathrm{~g},-1 \mathrm{~g}$ and $\mu \mathrm{g}$ LVF0670

Figure 10 Mean and rms profiles at $|\mathrm{x}|=40$ $\mathrm{mm}$ in $+1 \mathrm{~g},-1 \mathrm{~g}$ and $\mu \mathrm{g}$ LVF0670 

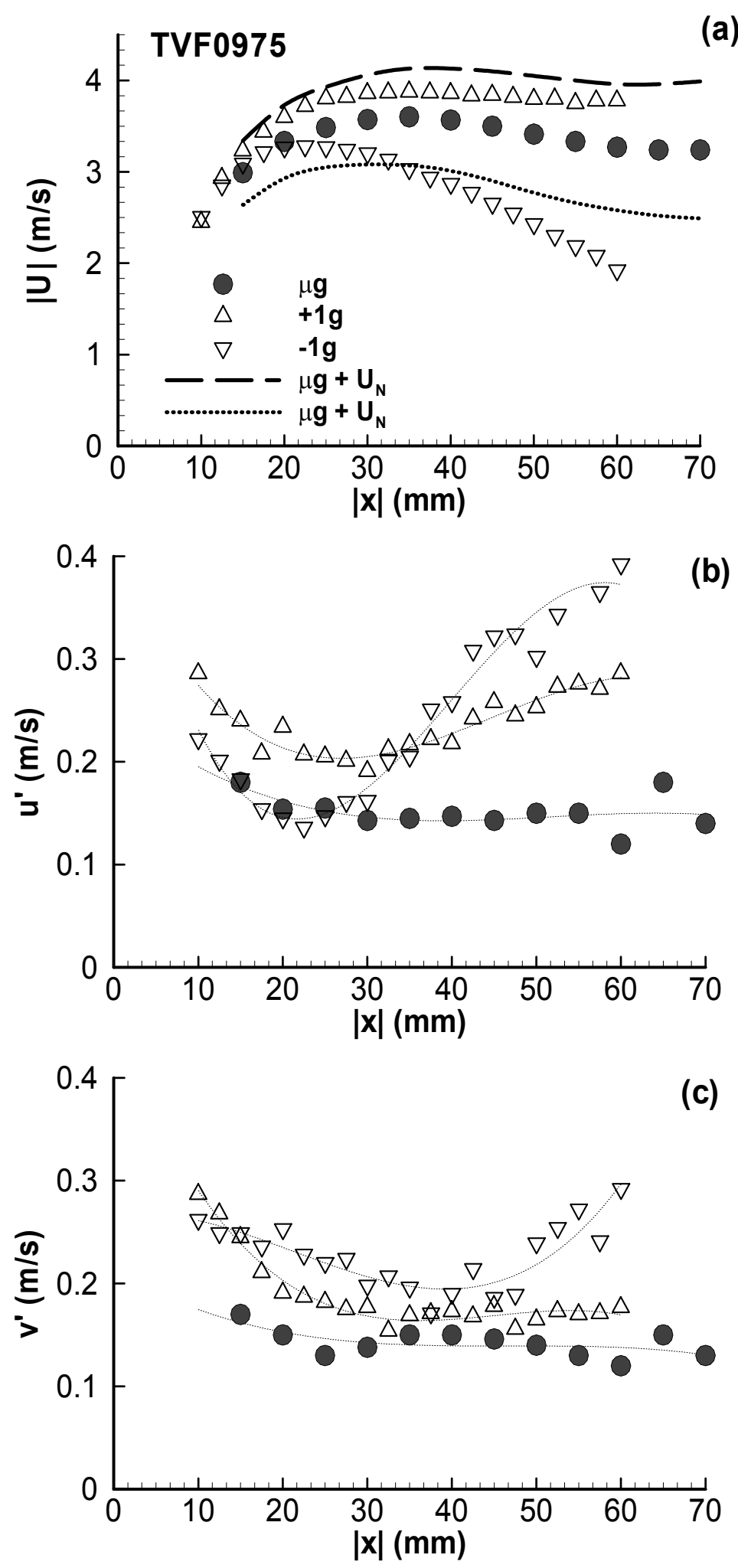

Figure 11 Mean and rms profiles on the centerline of $+1 \mathrm{~g},-1 \mathrm{~g}$ and $\mu \mathrm{g}$ TVF0975 

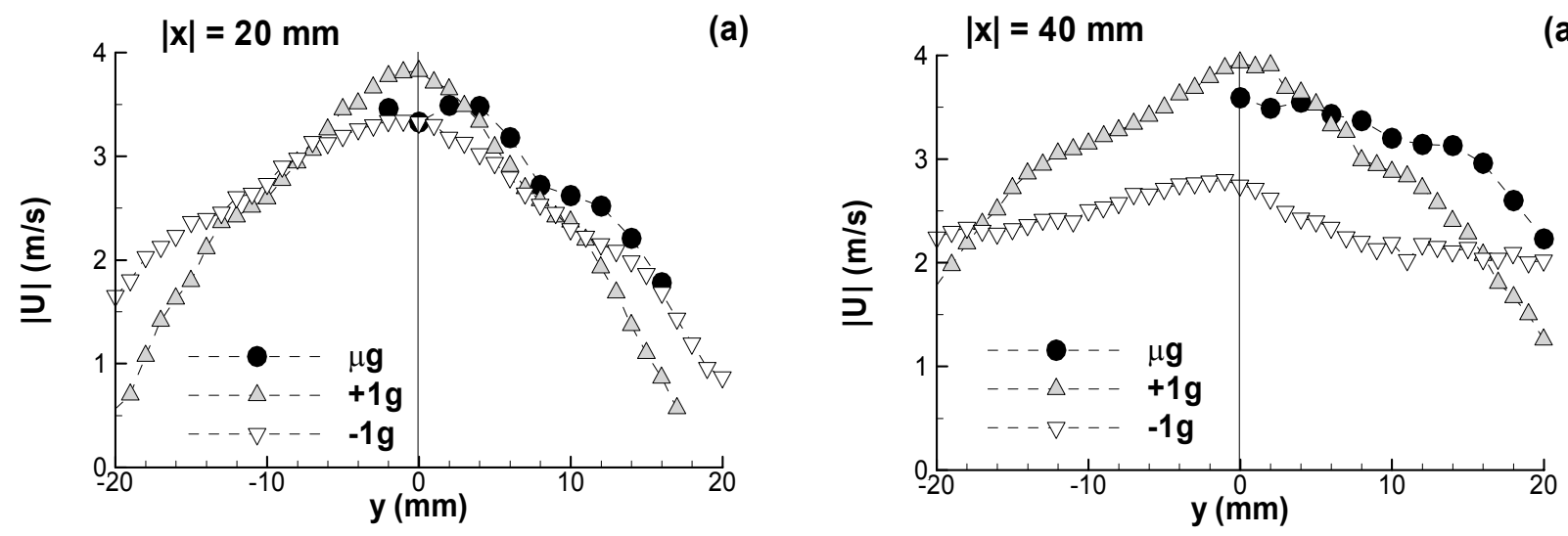

(a)
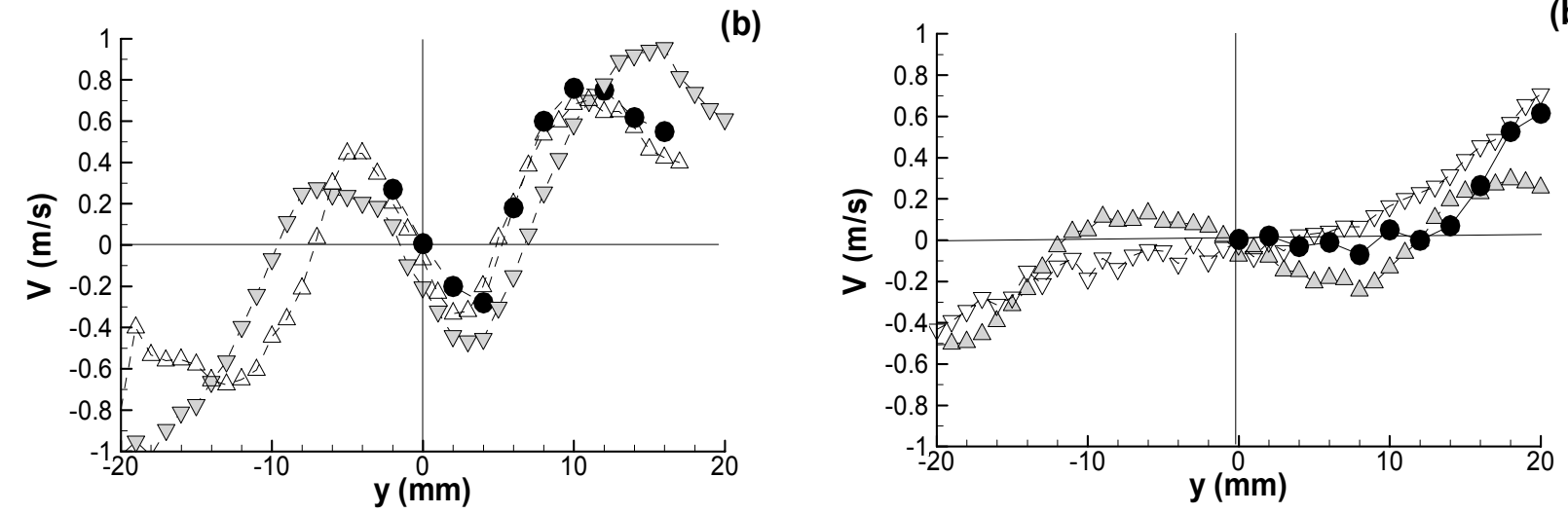

(b)
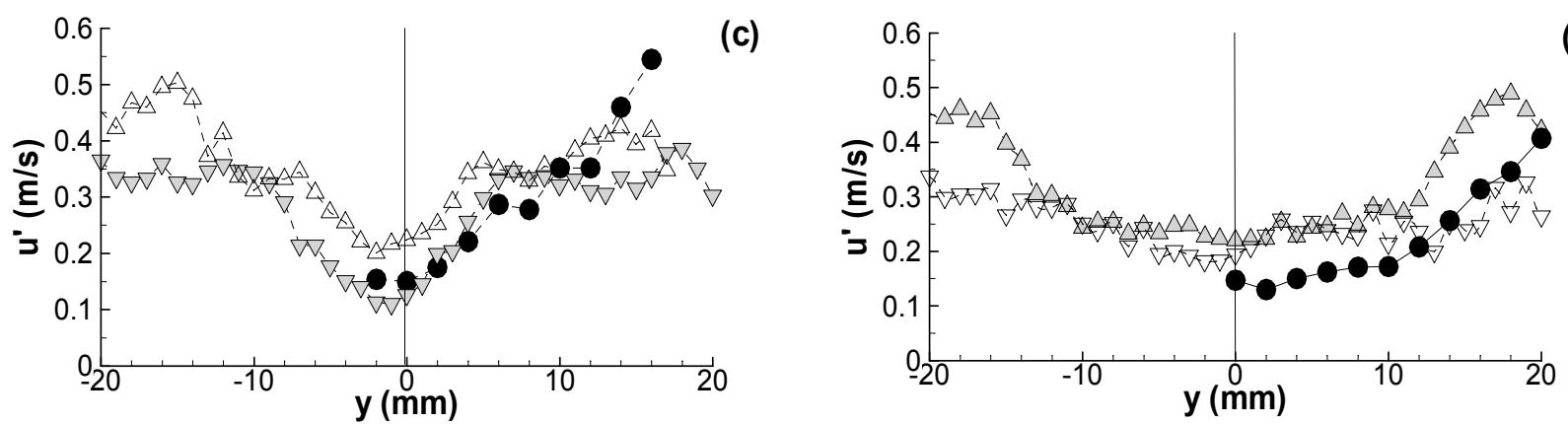

(c)

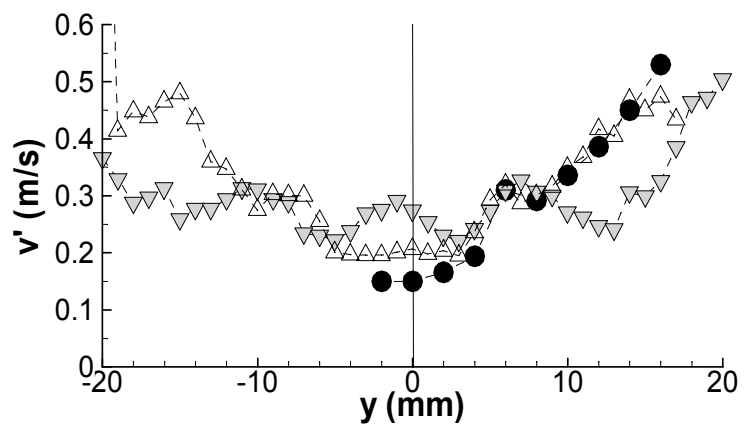

(d)

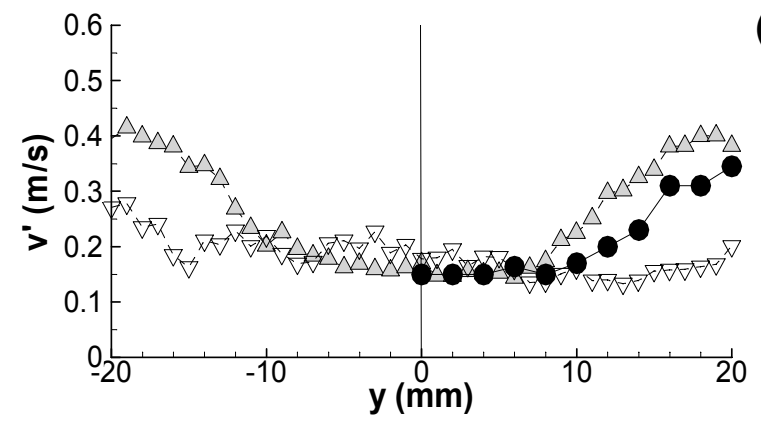

Figure 12 Mean and rms profiles at $|\mathrm{x}|=20 \mathrm{~mm}$ in $+1 \mathrm{~g},-1 \mathrm{~g}$ and $\mu \mathrm{g}$ TVF0975

Figure 13 Mean and rms profiles at $|\mathrm{x}|=40 \mathrm{~mm}$ in $+1 \mathrm{~g},-1 \mathrm{~g}$ and $\mu \mathrm{g}$ TVF0975 

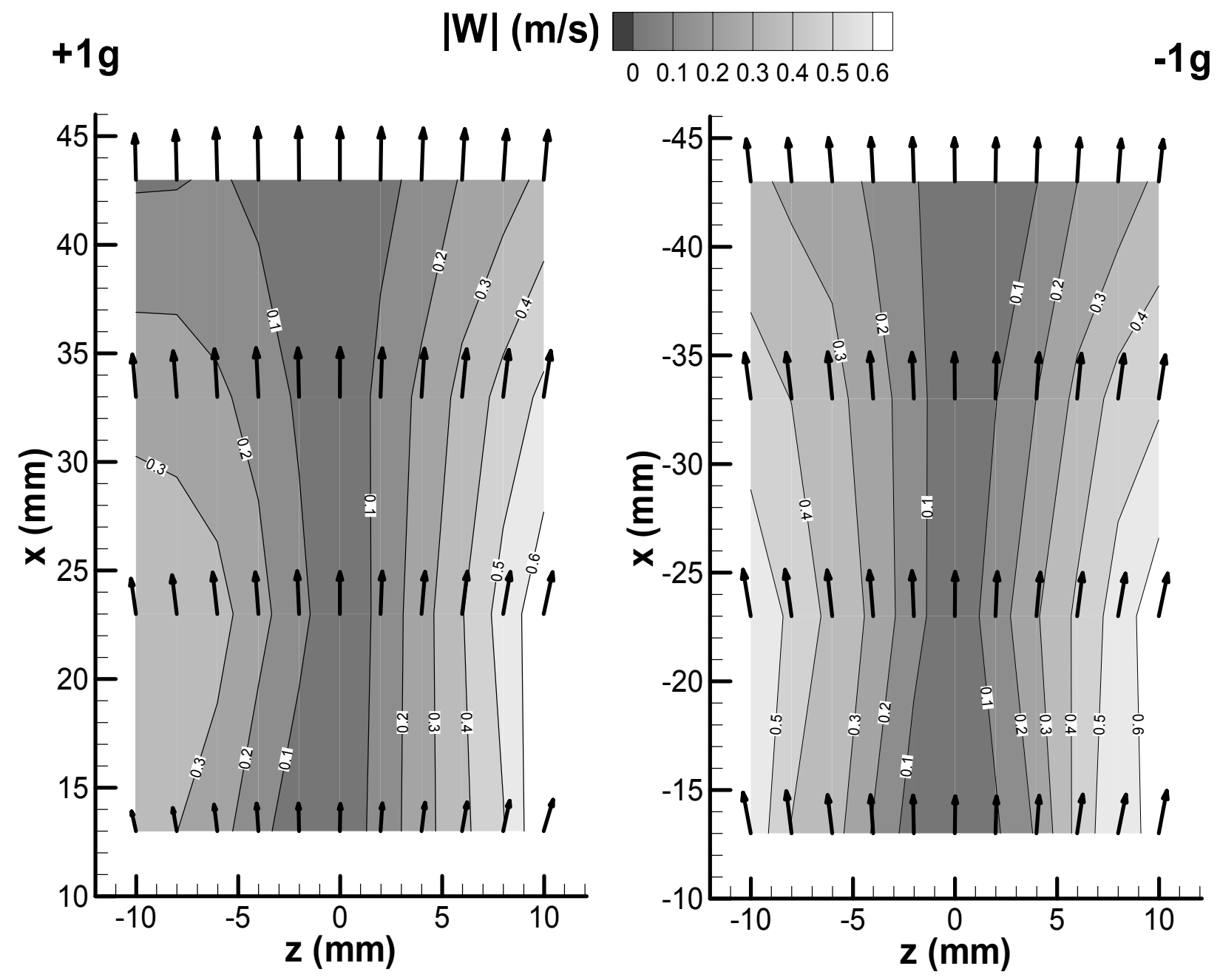

Figure 14 Mean velocity vectors and $|\mathrm{W}|$ contour on the $\mathrm{x}-\mathrm{z}$ plane of $+1 \mathrm{~g}$ and $-1 \mathrm{~g}$ TVF1065 

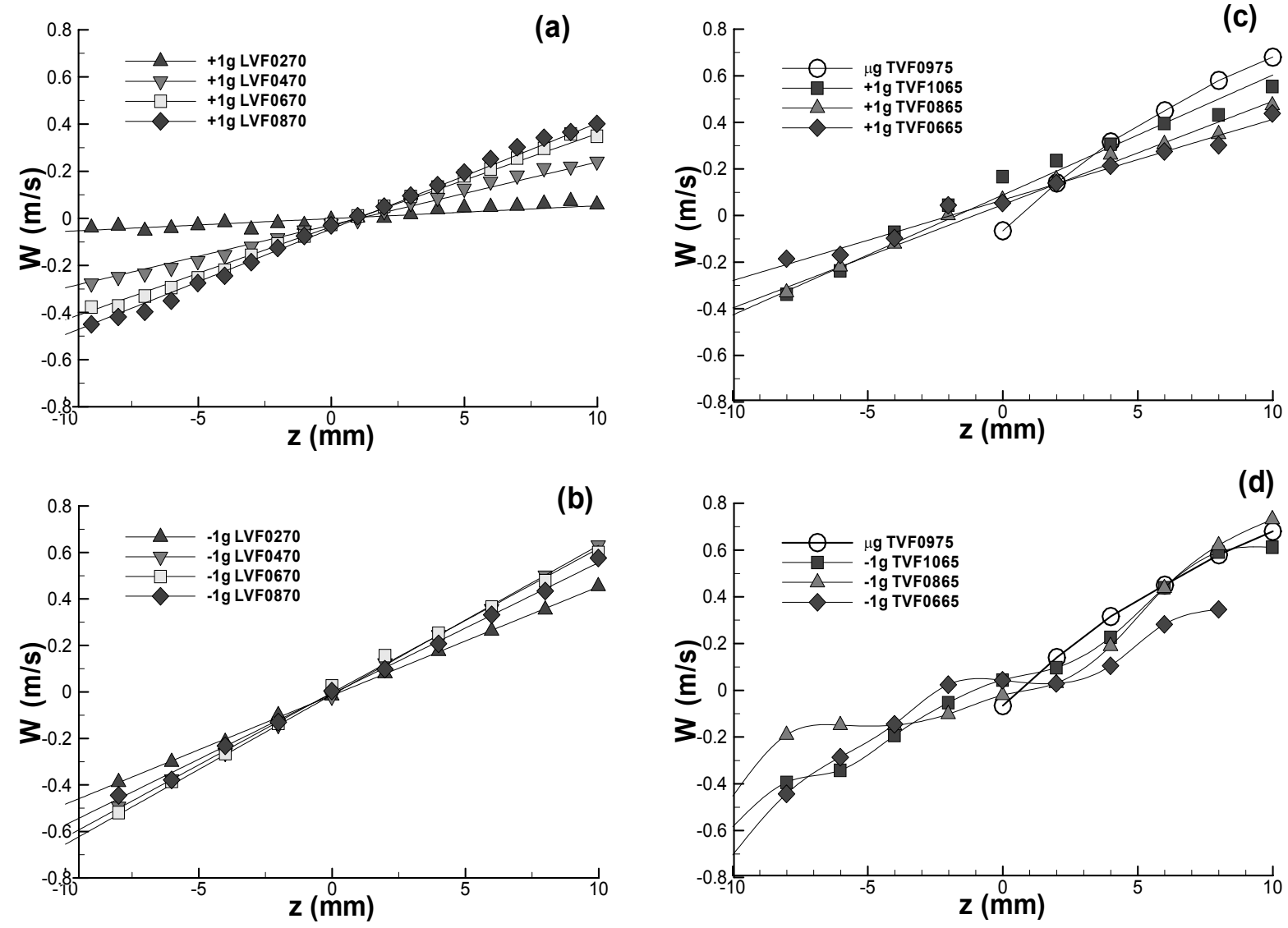

Figure 15 Mean W profiles laminar and turbulent v-flames in $+1 \mathrm{~g}$ and $-1 \mathrm{~g}$. 